\title{
GCU
}

Glasgow Caledonian

University

University for the Common Good

\section{Estimating excess length of stay due to healthcare-associated infections: a systematic review and meta-analysis of statistical methodology}

Manoukian, S.; Stewart, Sally; Dancer, S.; Graves, N.; Mason, H.; McFarland, A.; Robertson, C.; Reilly, J.

Published in:

Journal of Hospital Infection

DOI:

10.1016/j.jhin.2018.06.003

Publication date:

2018

Document Version

Author accepted manuscript

Link to publication in ResearchOnline

Citation for published version (Harvard):

Manoukian, S, Stewart, S, Dancer, S, Graves, N, Mason, H, McFarland, A, Robertson, C \& Reilly, J 2018,

'Estimating excess length of stay due to healthcare-associated infections: a systematic review and meta-analysis of statistical methodology', Journal of Hospital Infection, vol. 100, no. 2, pp. 222-235.

https://doi.org/10.1016/j.jhin.2018.06.003

\section{General rights}

Copyright and moral rights for the publications made accessible in the public portal are retained by the authors and/or other copyright owners and it is a condition of accessing publications that users recognise and abide by the legal requirements associated with these rights.

Take down policy

If you believe that this document breaches copyright please view our takedown policy at https://edshare.gcu.ac.uk/id/eprint/5179 for details

of how to contact us. 


\section{Estimating Excess Length of Stay due to Healthcare-Associated Infections: A Systematic Review and Meta-Analysis of Statistical Methodology.}

Sarkis Manoukian $\mathrm{PhD}^{1}$, Sally Stewart MSc ${ }^{5}$, Professor Stephanie Dancer MD, FRCPath ${ }^{2}$, Professor Nicholas Graves $\mathrm{PhD}^{3}$, Professor Helen Mason $\mathrm{PhD}^{1}$, Agi McFarland $\mathrm{MSc}^{5}$, Professor Chris Robertson $\mathrm{PhD}^{4}$, Professor Jacqui Reilly $\mathrm{PhD}^{5}$.

${ }^{1}$ Yunus Centre for Social Business and Health, Glasgow Caledonian University, Cowcaddens Road, Glasgow, G4 0BA, UK.

${ }^{2}$ Dept. of Microbiology, Hairmyres Hospital, NHS Lanarkshire,

${ }^{3}$ Institute of Health and Biomedical Innovation, Queensland University of Technology, Brisbane, Australia

${ }^{4}$ Department of Mathematics and Statistics, University of Strathclyde, 26 Richmond Street, Glasgow G1 1XH, UK

${ }^{5}$ School of Health and Life Sciences, Glasgow Caledonian University, Cowcaddens Road, Glasgow, G4 0BA, UK.

Declarations of interest: none

Corresponding author: Dr Sarkis Manoukian, Yunus Centre for Social Business and Health, Glasgow Caledonian University, M201 George Moore Building, Cowcaddens Road, Glasgow, G4 0BA. sarkis.manoukian@gcu.ac.uk. 


\section{$\underline{250 \text { word structured summary }}$}

Background: Healthcare-associated infection (HAl) affects millions of patients worldwide. $\mathrm{HAl}$ is associated with increased healthcare costs, owing primarily to increased hospital length of stay (LOS) but calculating these costs is complicated due to time-dependent bias. Accurate estimation of excess LOS due to HAI is essential to ensure we invest in costeffective infection prevention and control (IPC) measures.

Aim: To identify and review the main statistical methods that have been employed to estimate differential LOS between patients with, and without, HAl; to highlight and discuss potential biases of all statistical approaches.

Methods: A systematic review from 1997 to April 2017 was conducted in PUBMED, CINAHL, PROQUEST and ECONLIT databases. Studies were quality assessed using an adapted Newcastle-Ottawa Scale (NOS). Methods were categorised into time-fixed or time-varying with the former exhibiting time-dependent bias. We use two examples of meta-analysis to illustrate how estimates of excess LOS differ between different studies.

Findings: Ninety-two studies with estimates on excess LOS were identified. The majority of articles employed time-fixed methods (75\%). Studies using time-varying methods are of higher quality according to NOS. Studies using time-fixed methods overestimate additional LOS attributable to HAI. Undertaking meta-analysis is challenging due to a variety of study designs and reporting styles. Study differences are further magnified by heterogeneous populations, case definitions, causative organisms and susceptibilities.

Conclusions: Methodologies have evolved over the last 20 years but there is still a significant body of evidence reliant upon time-fixed methods. Robust estimates are required to inform investment in cost-effective IPC interventions. 


\section{Introduction}

Healthcare-Associated Infection (HAI) is a major issue for health providers, patients and public authorities worldwide.[1] The total annual number of patients with an HAl in European acute care hospitals was recently estimated at 3.2 million.[2] HAl has been associated with a significant impact on morbidity and mortality and can create substantial excess costs for health provision by prolonging hospital stay.[3] Accurate measurement of HAl costs is essential for developing cost-effective Infection Prevention and Control (IPC) measures. A major component of these costs can be captured by measuring the additional Length of Stay (LOS) due to HAI.[4, 5] This is complicated due to the fact that infection increases the duration of hospital stay but, at the same time, the risk of infection increases with duration of stay.[6] In addition, patients with longer LOS tend to be more at risk of HAI due to various characteristics and co-morbidities. HAl should be treated as a timedependent event that is not present on admission otherwise estimates of excess LOS are biased.[3, 6-8]

A number of literature reviews have focused on LOS and economic burden due to HAI. Shulgen et al reviewed two studies to illustrate the concept of time-dependent bias. [9] Mitchell et al published an integrative review on statistical methods used to examine LOS due to $C$. difficile infections with a focus on time-dependent bias.[10] Gandra et al examined antimicrobial resistance and discuss time-dependent bias when estimating cost.[11] De Angelis et al made the case for focusing on LOS when estimating HAI economic burden, reviewed methods to estimate LOS and criticised time-fixed methods that treat HAI as artificially present on admission.[12] Seven studies were reviewed by Nelson et al who highlighted the issue of time-dependent bias by comparing methods that treat HAl exposure as time fixed versus a time varying event.[13] Fukuda et al reviewed analytical methodologies for estimating additional healthcare cost of HAI.[14] They raise the importance of adjusting for LOS and employing good statistical methods. Stone et al reviewed economic analyses of $\mathrm{HAI}$ and recommended use of guidelines and appropriate methods.[15] Variability in methods estimating the economic cost of HAl arises for a number of reasons; these include differences in case definitions, patient populations and whether the study design is prospective or retrospective.[11] It has been suggested that 
meaningful comparisons can only be made if uniform definitions of rates are adopted along with standardised methods of data collection.[16] More recently Perencevich et al stated that stringent research standards are required to make the case for investing in IPC interventions, with a blueprint on how to achieve this.[17] It is uncertain whether these recommendations have been fully adopted. In the UK the main findings from the seminal Plowman study are still referenced but we should recognise the methodological limitations.[18]

In this paper we present a systematic review with two aims. First, to identify and review which statistical methods have been used to estimate differential LOS between patients with, and without, $\mathrm{HAl}$ and second, to assess the quality of studies and illustrate differences between the statistical methodologies with a particular focus on time-dependent bias. This is a unique review of studies with excess LOS estimates across all HAI types during the last twenty years. The review examines the current standard of research, identifies methods to estimate excess LOS due to HAI and proposes recommendations for the future.

\section{Methods}

This systematic review is PROSPERO registered (registration number: CRD42016050094); it adheres to recommendations in the Preferred Reporting Items for Systematic Reviews and Meta-Analyses (PRISMA) statement and guidance from the Campbell and Cochrane Economics Methods Group on incorporating economic evidence into systematic reviews. $[19,20]$

The literature was reviewed from 1st January 1997 to 30th April 2017 to identify relevant English language articles published in PUBMED, CINAHL, PROQUEST and ECONLIT databases. The search strategy combined the general "Cross Infection" MeSH heading with various nosocomial infection terms, major HAl types and economic or LOS terms (Appendix 1). HAl types were categorised based on European Centre for Disease Prevention and Control (ECDC) definitions.[21] Given the changing nature of acute hospital care, a 20 year period was chosen in order to include as many studies as possible while retaining studies that are still relevant today. 


\subsection{Selection criteria}

All studies were assessed for eligibility by applying the PICOS (population, intervention, comparison, outcomes and setting) question format.[19] Publications identified in the search were combined and duplicates removed. A two-step review process was undertaken. The first step consisted of a title-abstract review and the second step of a full article review. Two authors (SM, SS) independently examined the titles and abstracts identified by the search strategy to select articles. Studies that were identified by only one author (SM) were discussed by a third (AM) to determine if they met the eligibility criteria for inclusion in the Review. Disagreements were resolved by discussion between the three authors (SM, SS, AM).

The PICOS inclusion and exclusion criteria applied were:

- Population We included studies with adult inpatients that had a documented HAl in a health facility. Studies were excluded if they did not clearly distinguish between colonisation, community onset infections or HAl. Studies without a non-HAI comparison group were excluded.

- Intervention We included observational studies; interventions were not considered when including or excluding papers.

- Control/design We included case controlled and cohort studies. Case controlled studies allocated patients according to their HAl status. Commentaries and reviews were excluded.

- Outcome Studies were included if they attempted to measure and report LOS using any statistical method. Studies which did not report LOS data were excluded. Studies were required to report total LOS from admission to discharge. Studies measuring partial LOS were excluded (e.g. only reporting duration of stay in a single specialty).

- Setting We included studies in any health care setting with populations typical of acute care inpatient wards and critical care units. We excluded studies with selected populations; inpatients and outpatients or patients in residential care. 


\subsection{Data extraction}

An initial scoping review was undertaken for the selected papers with a set of classifications developed for analysis types. Six statistical methods were identified and divided into two high level groups. The first group treats HAl as present on admission or as time fixed and the second treats $\mathrm{HAl}$ as a time-dependent event or as time varying. Studies that did not match on the timing of infection will be referred to as Matching (Simple) and studies that matched on the timing to infection are referred to as Matching (Time). Group comparison, Matching (Simple) and regression techniques that do not take the timing of events into account are referred to as time-fixed. Matching (Time), Survival Analysis and Multistate Modelling control for the time-dependence of $\mathrm{HAl}$ are referred to as time-varying.[13] Survival analysis can also be a time-fixed approach but the identified survival analysis studies treated HAI as time-varying and therefore survival analysis was placed in the second group. A more detailed description of these methodologies is described within Supplementary material 5.

Extraction of data was performed by one investigator (SM). Two authors (SS, AM) checked $10 \%$ of this work for consistency. Any disagreements were resolved by consensus of these three authors. Data extraction was recorded on a Microsoft Excel template with the following columns: authors, year of publication, HAl type, organism (if reported), study design, statistical method, excess LOS due to HAl, confidence interval, sample size, year of data collection, journal title, country, country income classification, hospital setting, information on antibiotics (Yes/No) and discussion of time-dependent bias (Yes/No). Countries were grouped into high and middle income based on the World Bank country income classification.[22]

HAl type was defined based on the way papers reported their results. When papers reported outcomes for different HAl types we extracted these separately. We defined an HAI group where papers reported results for multiple types of HAI in a single measure. For example, a paper that reported the cost of $\mathrm{HAl}$ overall without distinguishing between the different subtypes would go into this group. Excess LOS due to HAI was not always available as a separate estimate since some studies reported LOS outcomes separately for an HAI and a non-HAl group. There were notable differences in the way studies reported their 
estimates and therefore we only report LOS outcomes in the studies selected for metaanalysis. Most studies reported standard deviations or confidence intervals but only standard errors or $p$-values were provided in some papers. Studies using regression methods or multistate modelling reported estimates of impact on LOS in excess days with a $95 \%$ confidence interval. When more than one method was used we extracted the main method and associated estimate. For example, when group comparison estimates were present along with estimates from another method we only extracted the latter. For bloodstream infection studies, we extracted multiple estimates for a single HAl (see section 2.4). We followed recommendations by the Cochrane collaboration for calculating confidence intervals in studies where this information was not provided.[19]

\subsection{Quality Assessment}

Quality assessment was carried out using Newcastle Ottawa Scale (NOS).[23, 24] NOS is a quality assessment tool for use on nonrandomized studies included in systematic reviews, specifically cohort and case-control studies. A star rating system is used to indicate the quality of a study, with a maximum assessment of nine stars.[24] Each criterion receives zero, one or two stars with more stars indicating higher compliance. As suggested by the Cochrane collaboration we modified NOS to represent issues specific to studies estimating excess LOS due to HAI.[19] Our version of NOS assesses study design, HAl case definitions and application of appropriate statistical methods. The main changes from the original NOS are defining the exposure as $\mathrm{HAI}$, the outcome as LOS, wording to reflect application of case definitions and allocation of one star to studies employing a time-varying statistical method. The rest of the criteria are the same as the original NOS. The only items where it was possible to receive two stars was for applying internationally recognised case definitions to records, e.g. CDC and ECDC, and for employing appropriate sampling strategies either as cohort or case control studies. The maximum number of stars possible was eight. One author (SM) assessed all included articles and two authors (SS, AM) checked $10 \%$ of this work for consistency. Any disagreements were resolved by consensus of the three authors. Supplementary material 3 details the version of NOS applied to the articles included in this review. Quality assessment was done for each LOS estimate separately. Table I shows the 
total number of stars awarded to each LOS estimate and Supplementary material 4 provides a detailed breakdown of quality assessment.

\subsection{Statistical Analysis}

Stata statistical software was used to conduct all statistical analyses.[25] A Wilcoxon-MannWhitney (WMW) test on the equality of means was performed to test if statistical methodology has an impact on article quality. When applying this test we excluded the NOS item on statistical methods since only time-varying methods could be allocated a star there. Meta-analysis: As discussed earlier the study designs showed a large amount of heterogeneity. In order to minimise differences in populations and potential impact on excess LOS, we focused on high income countries and chose two commonly occurring HAI types. The first meta-analysis focuses on estimates of impact of Bloodstream Infection (BSI) (17 studies) on LOS and the second on Gastrointestinal Infection (GI) (19 studies) caused by Clostridium difficile (CDI). Bloodstream infections are known to increase LOS and cause significant impact on patient morbidity and mortality.[26] HAI CDI was selected as it is a single causative organism associated with diarrheal disease and would provide an important difference on statistical methodology in the CDI meta-analysis. CDI HAI obviates the variation due to different causative organisms present in the BSI infections. The heterogeneity among studies was estimated by the $I^{2}$ statistic.[27] We used a randomeffects estimator to calculate pooled estimates of excess LOS due to HAI.[27, 28] The Stata metan routine was used to display meta-analysis results graphically in forest plots.[25, 29] For meta-analysis we extracted excess LOS estimates in days and calculated standard errors as recommended by the Cochrane collaboration. In cases where LOS of cases and controls was available separately, we extracted LOS for both of these groups and calculated the difference. Where different estimates for susceptible and resistant organisms were reported we extracted excess LOS for both. In the BSI group we extracted 31 excess LOS estimates from 17 studies where more than one method was used or information on more than one organism or different antibiotic susceptibilities were reported. In the CDI group we extracted one estimate from each study, 19 estimates in total. 


\section{Results}

The main characteristics of the studies included and the statistical methods identified are shown on Table I. There were: 23 studies[26, 30-51] with an estimate of impact of BSI on LOS; 22 studies[50, 52-72] with estimates from the impact of GI; 27 studies[37, 42, 43, 47, 50, 73-94] with estimates from surgical site infection (SSI); 26 studies[4, 43, 47, 50, 79, 80, 85, 95-113] with an average estimate from all types of $\mathrm{HAl}$; ten studies[35, 37, 42, 43, 45, $47,50,80,114,115]$ with estimates from urinary tract infection (UTI); eight studies[35, 37, $42,47,114,116-118]$ with estimates from pneumonia; four studies[43, 50, 80, 99] with estimates from lower respiratory tract infection (other than pneumonia); and one study[119] of bone and joint infection. In total we extracted 121 LOS estimates shown in supplementary material 1 from 92 studies.

See supplementary material 1 for a summary of the characteristics of the published studies. Some authors reported more than one infection type and therefore appear in multiple HAI groups. Studies employed data collected in multiple years and there was some overlap between selected studies. Table I shows the types of infections, statistical methodologies used to estimate excess LOS, country study design and year. As described earlier statistical methods were categorised in time-fixed and time-varying according to their treatment of the timing of HAI.[13]

There were 81 studies[4, 26, 31-39, 41-43, 46-71, 73-77, 79-95, 97, 99-102, 104-107, 109117,119 ] from high income countries, of which $40 \%$ took place in the US and $22 \%$ in the UK, Spain and Australia, and eleven studies[30, 40, 44, 45, 72, 78, 96, 98, 103, 108, 118] from middle income countries. The majority $(80 \%)$ of studies were cohort studies and we included 18 studies with a case-control design. The case-control design applies to the sampling strategy where one or more controls were chosen for each HAI case. These type of studies are also known as case-control with follow up[120]. The majority of the studies collected data during the period 2005 to 2012 . The most frequent statistical method employed in the included articles is simple matching (31 studies, $34 \%$ ) followed by regression (24 studies, 26\%), group comparison (14 studies, 15\%), matching on time (12 studies, 13\%), multistate modelling (9 studies, $10 \%$ and survival analysis ( 2 studies, $2 \%$ ). There were 12 studies that investigated more than one HAl types and from these we 
extracted more than one estimates, one for each HAI.[35, 37, 42, 43, 45, 47, 50, 79, 80, 85, $99,114]$

Figure 2 shows trends in statistical techniques in published articles over the last two decades. Time-fixed methods are the largest proportion (73\%) of statistical techniques used to estimate excess LOS. In our sample studies using time-varying methods appear in 2006 and 59\% of these used matching on time to infection techniques.[85] Group comparison studies are still being published and 12\% of articles have used this method since 2006. Overall, only $32 \%$ of studies published since 2006 have used time-varying methods.

Figure 3 shows that time-fixed methods have been used in the majority of articles in every year except 2008. Time-fixed methods continue to be the most common methodology used in HAI studies. This review included two survival analysis studies and nine multistate modelling studies (Table I). Nine articles from middle income countries used either a group comparison $[72,96,98,108,118]$ approach or a simple matching method.[40, 44, 78, 103] One article from the middle income country group used a regression model[45] and one article used matching on the time to infection.[30]

Quality assessment NOS scores of seven or eight were considered as high-quality, five or six as moderate quality and low quality for less than five. Approximately $57 \%$ of estimates were of high quality receiving seven or eight stars. Articles using time-varying methods are of higher quality than articles with time-fixed methods. Figure 4 summarises the results of the quality assessment by type of statistical method. NOS allocates seven stars out of eight to study design. Articles using time-varying methods scored significantly $(z=3.172, P<.002)$ higher in the quality assessment. When performing the WMW test we excluded the NOS item that is related to methods since only time-varying methodologies could be awarded a star and we wanted to compare quality as captured by the NOS items on study design. One reason that time-fixed methods were assessed to be of lower quality is that only $55 \%$ of these applied case definitions to identify cases. $23 \%$ of the time-fixed studies scored zero stars in the relevant NOS item as they used retrospective case ascertainment using (International Classification of Disease) ICD codes or treatment.[121] 


\subsection{Meta-analyses}

For the BSI meta-analysis two studies reported results for more than one organism.[26, 32] Five studies reported results for susceptible and resistant organisms separately.[26, 33, 36, $46,49]$ Three studies reported results using more than one statistical method. $[33,47,51]$ Time-fixed methods consistently produce higher estimates of HAI impact on LOS with larger confidence intervals. In the BSI meta-analysis the focus is on within-study differences and we found that the causative organism and susceptibility have a big impact on excess LOS due to HAl; these should always be taken into account when calculating the economic impact of BSI in different settings.

Figure 5 presents the results of the meta-analysis in the BSI articles grouped by statistical method. There is considerable variability in the estimates with a range of 1.2 to 26.4 excess days due to HAl. Among studies that used more than one statistical method two studies show that estimated excess LOS can increase substantially if patient characteristics and comorbidities are ignored by using group comparison as opposed to regression or simple matching. $[33,47]$ Vrijens et al show that ignoring BSI as a time-dependent event by using time-fixed methods more than doubles the estimated excess LOS.[51] Heterogeneity is very high in every group with the matching on time group having the lowest $I^{2}$ of $82 \%$. One reason for the high heterogeneity is that these studies examine a range of organisms associated with BSI. Studies that did not estimate impact of specific organism but had access to laboratory results reported that $S$. aureus was one of the most common causes of BSI in their samples.[32, 39, 46, 51] Stewardson et al estimate the impact of susceptible and resistant Enterobacteriaceae and S. aureus BSI using multistate modelling and find that the estimated impact of the susceptible BSI infections on LOS approximately doubles when $S$. aureus is the causative agent.[26] The study by Barnett et al shows that BSI caused by Gram positive bacteria have a much greater impact on LOS than BSI caused by Gram negative bacteria.[32] Figure 5 shows that antimicrobial resistance (AMR) increases estimated LOS and there are noticeable differences between causative pathogens. $[26,32,33,49]$ The variability in the BSI studies contrasts to the second meta-analysis focusing on a single organism to isolate the impact of statistical method on the estimates. 
We extracted 19 estimates from 19 studies estimating excess LOS due to Healthcare Associated (HA) CDI in high income countries (Figure 6).[52-63, 65-71] The HA CDI studies focus on a single infection type caused by the same organism and estimates in each statistical group were homogenous as shown by the low $I^{2}$ scores within each analysis group in Figure 6 . The overall $I^{2}$, which can be calculated by analysing studies as a single group, was very high (99.7\%) and resembled $I^{2}$ scores in the BSI studies. Figure 6 shows that the results should be analysed separately for each statistical methodology. The CDI results display a large variability in LOS estimates on the impact of CDI with a range of 1 to 16 excess days. Since $\mathrm{CDI}$ is a commonly occurring $\mathrm{HAl}$ even a small number of extra days can have a significant impact on cost estimates due to CDI.[122] Time-fixed methods produce consistently higher estimates of excess LOS due to CDI. This finding is particularly evident in studies using regression methods and simple matching studies, which show higher heterogeneity and much higher and uncertain estimates of LOS when compared to timevarying methods. The impact of BSI and CDI on LOS is consistently overestimated when time-fixed methods are used.

\section{Discussion}

This systematic review found that there are six main statistical techniques which have been used over the last 20 years to assess excess LOS due to HAI. These methods can be grouped in time-fixed and time-varying according to their treatment of time-dependence. We found a significant body of evidence that does not take into account the time-dependent nature of HAl due to the use of time-fixed methods. Even though time-varying methods appeared more than ten years ago the majority of articles in high income countries still use time-fixed methods to estimate excess LOS due to HAl. In middle income countries (where sophisticated data are not routinely collected due to funding constraints) we only identified one study that controls for time-dependence.[30]

The ability to synthesise evidence from multiple studies is key if policymakers and researchers are willing to model the cost-effectiveness of IPC interventions. Despite a large number of publications on each type of infection it is challenging and sometimes inappropriate to synthesise evidence due to the fact researchers use different study designs, statistical methods and reporting styles. There are inherent difficulties in HAI literature due 
to the range of different infection types, settings, patient types, organisms and AMR. However, we found that papers often magnify these differences by using time-fixed methods. This limits our ability to synthesise evidence, even in cases where studies investigate a single HAl type or a single organism. When looking at a single infection (BSI) the meta-analysis has shown that causative organisms and antibiotic resistance have a large impact on the excess LOS estimates. Where synthesising evidence appeared possible (CDI) meta-analysis showed that the choice of statistical method can have a highly distortive effect on excess LOS estimates. The meta-analysis of the BSI studies suggests that defining a high level infection type (such as BSI) is not sufficient to perform synthesis when trying to estimate economic impact since this can hide substantial heterogeneity between studies. So other than choosing studies that account for time-dependence bias it is also important to be clear about organism identity, patient conditions and AMR in the studies of the metaanalysis. The meta-analysis of CDI studies confirmed previous work which suggests timefixed methods overestimate the burden of HAI when compared to time-varying.[113] We suggest that researchers take into account all the above when performing meta-analysis to estimate economic cost of HAl.

IPC planning at international, national or local levels requires accurate cost estimates and therefore excess LOS precision. IPC measures aim to prevent HAI cases in order to improve clinical effectiveness and maximise health benefits.[13] Identifying which combination of $\mathrm{HAl}$ and patient characteristics causes the greatest economic burden should help focus investment in interventions that give the greatest return. The main cost attributable to $\mathrm{HAl}$ is the additional stay in the hospital.[5, 7, 77, 123] Preventing HAl can lead to released bed days, reduction in waiting times and the ability to treat more patients. Modelling studies that synthesise evidence from different sources can inform policy related to IPC measures.[124] Nevertheless, it is of the utmost importance that modelling studies are based on well-designed studies otherwise recommendations on cost-effectiveness of IPC interventions become unreliable.

Our results agree with previous work, which suggests that estimates from time-varying methods that control for time-dependent bias should be adopted when making policy decisions. $[7,12,13]$ Time-fixed methods suffer from time-dependent bias and studies employing such methods are of lower quality overall. Each study is conducted in inherently 
different circumstances with differences in characteristics of the study population and methodologies. There are also differences in the way LOS outcomes are reported complicating the process of synthesising results. Some studies were excluded from this review because it was not clear if cases were healthcare associated infection, colonisation, community acquired infection or a combination. Since IPC interventions are designed to target $\mathrm{HAl}$ and not community onset infection, only studies that clearly show that outcomes are HAl-specific should be used for planning policy.

There is already an acknowledged requirement for structured reporting of observational studies with the STROBE statement and economic evaluation studies with the CHEERS statement. Studies investigating HAl burden are observational studies which fall within the scope of STROBE. $[125,126]$ Analytical methodologies have evolved and reporting guidelines have not accounted for all these developments and should also be updated. Studies that fully meet the STROBE recommendations will not necessarily avoid time-dependent bias or measurement bias in their results. Our recommendation is that additional aspects of study design and reporting should be considered especially within studies reporting $\mathrm{HAl}$ and antimicrobial resistance.

Overall recommendations are:

1) Studies can have either a cohort or a case-control design but always ensure that the comparator group is clearly defined especially when reporting AMR outcomes.

2) Studies should employ appropriate case definitions, ideally internationally recognised definitions applied to records and clearly distinguish between $\mathrm{HAl}$ and community-onset or colonisation.

3) Studies should collect data on the timing of events and control for time-dependent bias by using a time varying analytical methodology

4) Studies should report results from a multi-state model or if these are not available patient-days of HAI and non-HAI patients.

5) Studies must clearly state if LOS was measured from admission to discharge or if LOS was partially measured e.g. LOS within ICU.

This review indicates that excess LOS estimates based on statistical methods that treat HAI as a time-varying exposure show a shorter estimated extra stay. This means that HAl costs may have been overestimated. $[5,6,10,13,68,113,127]$ Time-dependent bias and different 
statistical methods lead to highly variable estimates, which might lead to inefficient policies. Beyersmann et al show that time-dependant bias is large in methods such as regression methods and survival analysis that do not normally treat HAl as a time-varying exposure.[128] Common regression methods cannot control for the timing of events and caution should be exercised when applying or interpreting regression results.[129] Regression methods to estimate excess LOS should only be used for associations rather than causal inference.[41] Survival analysis is normally a time-fixed method but it can be adapted; the two survival analysis studies included in this review treat HAI as timevarying.[58, 85]

Matching methods should match on time to infection requiring the control patient to have spent an equivalent time in hospital before the infection as the case.[36, 51] This will not completely eliminate time-dependent bias but it will significantly reduce it. Nelson et al compare three estimation strategies and show that matching on the time to infection can substantially reduce time-dependence bias.[113] Matching on time to infection should be ideally performed by using incidence density sampling. This produces similar estimates to multistate modelling although with less precision and wider confidence intervals.[3] A combination of these two methods was used by Barnett et al who applied multistate modelling to a sample that was matched using incidence density sampling.[32] The recommended approach to estimate excess LOS is multistate modelling.[4] Wolkewitz et al (2017) show that if information on event counts or patient days is available it is possible to perform basic multistate analysis.[130] However, a limitation of multistate models in the past was that they were not able to control for patient characteristics. Stewardson et al demonstrate an approach to indirectly control for age and comorbidities using a multilevel model.[26] In most cases HAI patients have greater severity of illness and comorbidities when compared with non-HAl patients. Since severity of illness and comorbidities are also predictors of LOS it is important to control for these because such variables may distort the relationship between infection and LOS.[17]

One reason for the lack of studies that control for time-dependent bias may be the data requirements for these methods, e.g. knowing the day the infection began during a patient's hospital stay. Only if this information is available can researchers employ statistical methods that control for time-dependent bias. We identified US studies that frequently use the 
National Inpatient Sample (NIS).[31, 35, 56, 57, 65, 71, 115, 119] These studies use ICD codes to identify cases but NIS data do not provide information on the timing of infection forcing researchers to use time-fixed methods to estimate impact of HAI on LOS. These studies received the lowest scores in the quality assessment and estimates should be treated with caution. Barnett et al published a detailed description of how time-dependent data can be organised for use in statistical models.[129] An estimate of only a few days excess stay in hospital can have a large impact on total cost. For example, the cost of an excess bed-day in 2015-2016 has been estimated at $£ 306$ and there were 1,398 CDI cases in 2016 in Scotland.[131, 132] Every extra day of estimated excess LOS due to CDI would appear to cost an additional $£ 427,788$ to the Scottish NHS. We recognise that for this calculation we have not used unit costs that reflect the opportunity cost of the bed-day and these would be expected to be lower than $£ 306$.[133] Even though the exact figure can be challenged on the basis of not being a pure opportunity cost we have seen that time-fixed methods can overestimate this effect for CDI by up to seven times. Irrespective of using accounting or opportunity costs excess LOS should be estimated using time-varying methods.

We propose that methods that minimise time-dependent bias are used to inform models of cost-effectiveness because only after establishing estimates through appropriate research methods can we combine findings from multiple studies to inform policy decisions. Following the recommendations of this review would improve our ability to undertake both meta-analysis and modelling studies. This will help to develop more precise estimates of the effects of interventions by ensuring use of studies with as low bias as possible especially measurement and time-dependent bias. In general, more and better designed studies are needed in order to provide accurate data to support effective and efficient IPC interventions.[14]

\section{Conclusions}

Accurate quantification of additional costs of HAl is essential for developing cost-effective IPC measures. A range of statistical analyses have been used to address the question of excess LOS as a result of HAI. Availability of specific data item and study design can dictate 
researchers' ability to employ time-varying statistical techniques. As with all research that requires data collection there is a balance to be struck in terms of resource intensive data collection and requirements for analysis. When measuring economic impact, a major component of $\mathrm{HAl}$ costs can be captured by measuring the additional LOS due to these infections. We recommend that studies collect accurate information on the timing of key events such as time of admission, time of infection and time of discharge. Combining this information with patient characteristics and co-morbidities with appropriate statistical methods such as survival analysis; multistate modelling; or matching on time to infection minimises bias when estimating impact on LOS. Better study design, analytical techniques and reporting are needed to improve the quality of evidence worldwide. Further research is needed to identify the impact of HAl, including in middle and low income countries where data availability is limited due to funding constraints.[134]

\section{Acknowledgments}

This study was funded by Health Protection Scotland and is part of the Evaluation of Cost of Nosocomial Infection (ECONI) study. Glasgow Caledonian University serves as the host institution for this study and collaborators are the University of Strathclyde, Nicholas Graves as an Independent Consultant, NHS Lothian and NHS Lanarkshire.

\section{Role of the funding source}

The study sponsor had no role in study design, data collection, data analysis, data interpretation, or reporting. The corresponding author had final responsibility for the decision to submit for publication. All authors have read and agreed to the final draft before submission. 


\section{$7 \quad$ References}

[1] World Health Organization. Report on the burden of endemic health care-associated infection worldwide. Geneva: World Health Organization 2011.

[2] European Centre for Disease Prevention and Control. Point prevalence survey of healthcareassociated infections and antimicrobial use in European acute care hospitals. Stockholm: ECDC 2013; 1-207.

[3] Schumacher M, Allignol A, Beyersmann J, Binder N, Wolkewitz M. Hospital-acquired infections--appropriate statistical treatment is urgently needed! Int J Epidemiol 2013; 42: $1502-8$.

[4] Arefian $\mathrm{H}$, Hagel $\mathrm{S}$, Heublein $\mathrm{S}$ et al. Extra length of stay and costs because of health careassociated infections at a German university hospital. Am J Infect Control 2016; 44: 160-6.

[5] Graves N, Harbarth S, Beyersmann J, Barnett A, Halton K, Cooper B. Estimating the cost of health care-associated infections: mind your p's and q's. ClinInfectDis 2010; 50: 1017-21.

[6] Beyersmann J, Kneib T, Schumacher M, Gastmeier P. Nosocomial infection, length of stay, and time-dependent bias. Infect Control Hosp Epidemiol 2009; 30: 273-6.

[7] Barnett AG, Beyersmann J, Allignol A, Rosenthal VD, Graves N, Wolkewitz M. The timedependent bias and its effect on extra length of stay due to nosocomial infection. Value Health 2011; 14: 381-6.

[8] Beyersmann J, Gastmeier P, Wolkewitz M, Schumacher M. An easy mathematical proof showed that time-dependent bias inevitably leads to biased effect estimation. Journal of Clinical Epidemiology 2008; 61: 1216-21.

[9] Schulgen G, Kropec A, Kappstein I, Daschner F, Schumacher M. Estimation of extra hospital stay attributable to nosocomial infections: heterogeneity and timing of events. J Clin Epidemiol 2000; 53: 409-17.

[10] Mitchell BG, Gardner A. Prolongation of length of stay and Clostridium difficile infection: a review of the methods used to examine length of stay due to healthcare associated infections. AntimicrobResist InfectControl 2012; 1: 14.

[11] Gandra S, Barter DM, Laxminarayan R. Economic burden of antibiotic resistance: how much do we really know? Clinical microbiology and infection : the official publication of the European Society of Clinical Microbiology and Infectious Diseases 2014; 20: 973-80.

[12] De Angelis G, Murthy A, Beyersmann J, Harbarth S. Estimating the impact of healthcareassociated infections on length of stay and costs. Clinical microbiology and infection : the official publication of the European Society of Clinical Microbiology and Infectious Diseases 2010; 16: 1729-35.

[13] Nelson RE, Nelson SD, Khader K et al. The Magnitude of Time-Dependent Bias in the Estimation of Excess Length of Stay Attributable to Healthcare-Associated Infections. Infect Control Hosp Epidemiol 2015; 36: 1089-94.

[14] Fukuda H, Lee J, Imanaka Y. Variations in analytical methodology for estimating costs of hospital-acquired infections: a systematic review. The Journal of hospital infection 2011; 77: 93-105.

[15] Stone PW, Braccia D, Larson E. Systematic review of economic analyses of health careassociated infections. American Journal of Infection Control 2005; 33: 501-9.

[16] Freeman J, McGowan JE, Jr. Methodologic issues in hospital epidemiology. I. Rates, casefinding, and interpretation. Rev Infect Dis 1981; 3: 658-67.

[17] Perencevich EN, Stone PW, Wright SB, Carmeli Y, Fisman DN, Cosgrove SE. Raising Standards While Watching the Bottom Line: Making a Business Case for Infection Control. InfectControl HospEpidemiol 2007; 28: 1121-33.

[18] Plowman R, Graves N, Griffin MAS et al. The Socio-economic Burden of Hospital Acquired Infection. Volume 1. London: Public Health Laboratory Service 1999.

[19] Higgins JPT, Green S. General methods for Cochrane reviews. Cochrane Handbook for Systematic Reviews of Interventions, Version 5.1.0 edn.: The Cochrane Collaboration 2011. 
[20] Liberati A, Altman DG, Tetzlaff J et al. The PRISMA statement for reporting systematic reviews and meta-analyses of studies that evaluate healthcare interventions: explanation and elaboration. BMJ 2009; 339: b2700.

[21] European Centre for Disease Prevention and Control. Point prevalence survey of healthcareassociated infections and antimicrobial use in European acute care hospitals- Protocol version 5.3. Stockholm: ECDC 2016; 1-83.

[22] The World Bank. Countries. (accessed 2017 Mar 6). http://www.worldbank.org/en/country

[23] Wells G, Shea B, O'Connell D et al. The Newcastle-Ottawa Scale (NOS) for assessing the quality of nonrandomised studies in meta-analyses. (accessed 2016 Nov 11). http://www.ohri.ca/programs/clinical epidemiology/oxford.asp

[24] Wells G, Shea B, O'Connell J, Robertson J, et al. The Newcastle-Ottawa Scale (NOS) for assessing the quality of nonrandomised studies in meta-analysis [Abstract]. 3rd Symposium on Systematic Reviews: Beyond the Basics, Oxford, UK: 2000.

[25] StataCorp. Stata Statistical Software Release 13. College Station, TX: StataCorp LP, 2013.

[26] Stewardson AJ, Allignol A, Beyersmann J et al. The health and economic burden of bloodstream infections caused by antimicrobial-susceptible and non-susceptible Enterobacteriaceae and Staphylococcus aureus in European hospitals, 2010 and 2011: a multicentre retrospective cohort study. Euro surveillance : bulletin Europeen sur les maladies transmissibles = European communicable disease bulletin 2016; 21: pii=30319.

[27] Higgins JP, Thompson SG, Deeks JJ, Altman DG. Measuring inconsistency in meta-analyses. BMJ 2003; 327: 557-60.

[28] Lau J, loannidis JP, Schmid CH. Quantitative synthesis in systematic reviews. Ann Intern Med 1997; 127: 820-6.

[29] Harris RJ, Bradburn MJ, Deeks JJ, Harbord R, Altman DG, Sterne JAC. metan: fixed- and random-effects meta-analysis. Stata Journal 2008; 8: 3-28.

[30] Al-Rawajfah OM, Cheema J, Hewitt JB, Hweidi IM, Musallam E. Laboratory-confirmed, health care-associated bloodstream infections in Jordan: a matched cost and length of stay study. Am J Infect Control 2013; 41: 607-11.

[31] Al-Rawajfah OM, Hewitt JB, Stetzer F, Cheema J. Length of stay and charges associated with health care-acquired bloodstream infections. Am J Infect Control 2012; 40: 227-32.

[32] Barnett AG, Page K, Campbell $M$ et al. The increased risks of death and extra lengths of hospital and ICU stay from hospital-acquired bloodstream infections: a case control study. BMJ Open 2013; 3: e003587.

[33] Butler AM, Olsen MA, Merz LR et al. Attributable costs of enterococcal bloodstream infections in a nonsurgical hospital cohort. InfectControl HospEpidemiol 2010; 31: 28-35.

[34] Caballero-Granado FJ, Becerril B, Cuberos L, Bernabeu M, Cisneros JM, Pachon J. Attributable mortality rate and duration of hospital stay associated with enterococcal bacteremia. Clin Infect Dis 2001; 32: 587-94.

[35] Dasenbrock HH, Rudy RF, Smith TR et al. Hospital-Acquired Infections after Aneurysmal Subarachnoid Hemorrhage: A Nationwide Analysis. World neurosurgery 2016; 88: 459-74.

[36] de Kraker ME, Wolkewitz M, Davey PG et al. Clinical impact of antimicrobial resistance in European hospitals: excess mortality and length of hospital stay related to methicillinresistant Staphylococcus aureus bloodstream infections. Antimicrob Agents Chemother 2011; 55: 1598-605.

[37] Glied S, Cohen B, Liu J, Neidell M, Larson E. Trends in mortality, length of stay, and hospital charges associated with health care-associated infections, 2006-2012. Am J Infect Control 2016; 44: 983-9.

[38] Grupper M, Sprecher H, Mashiach T, Finkelstein R. Attributable mortality of nosocomial Acinetobacter bacteremia. Infect Control Hosp Epidemiol 2007; 28: 293-8. 
[39] Kaye KS, Marchaim D, Chen TY et al. Effect of nosocomial bloodstream infections on mortality, length of stay, and hospital costs in older adults. J Am Geriatr Soc 2014; 62: 30611.

[40] Kothari A, Sagar V, Ahluwalia V, Pillai BS, Madan M. Costs associated with hospital-acquired bacteraemia in an Indian hospital: a case-control study. J Hosp Infect 2009; 71: 143-8.

[41] Molina J, Penuela I, Lepe JA et al. Mortality and hospital stay related to coagulase-negative Staphylococci bacteremia in non-critical patients. J Infect 2013; 66: 155-62.

[42] Peng MM, Kurtz S, Johannes RS. Adverse outcomes from hospital-acquired infection in Pennsylvania cannot be attributed to increased risk on admission. Am J Med Qual 2006; 21: 17S-28S.

[43] Plowman R, Graves N, Griffin MA et al. The rate and cost of hospital-acquired infections occurring in patients admitted to selected specialties of a district general hospital in England and the national burden imposed. J Hosp Infect 2001; 47: 198-209.

[44] Primo MG, Guilarde AO, Martelli CM, Batista LJ, Turchi MD. Healthcare-associated Staphylococcus aureus bloodstream infection: length of stay, attributable mortality, and additional direct costs. Braz J Infect Dis 2012; 16: 503-9.

[45] Rattanaumpawan P, Thamlikitkul V. Epidemiology and economic impact of health careassociated infections and cost-effectiveness of infection control measures at a Thai university hospital. Am J Infect Control 2017; 45: 145-50.

[46] Riu M, Chiarello P, Terradas R et al. Cost Attributable to Nosocomial Bacteremia. Analysis According to Microorganism and Antimicrobial Sensitivity in a University Hospital in Barcelona. PLOS ONE 2016; 11: e0153076.

[47] Roberts RR, Scott RD, 2nd, Hota B et al. Costs attributable to healthcare-acquired infection in hospitalized adults and a comparison of economic methods. Med Care 2010; 48: 1026-35.

[48] Song X, Srinivasan A, Plaut D, Perl TM. Effect of nosocomial vancomycin-resistant enterococcal bacteremia on mortality, length of stay, and costs. Infection control and hospital epidemiology 2003; 24: 251.

[49] Stewardson A, Fankhauser C, De Angelis G et al. Burden of bloodstream infection caused by extended-spectrum beta-lactamase-producing enterobacteriaceae determined using multistate modeling at a Swiss University Hospital and a nationwide predictive model. Infect Control Hosp Epidemiol 2013; 34: 133-43.

[50] Vrijens F, Hulstaert F, Devriese S, van de Sande S. Hospital-acquired infections in Belgian acute-care hospitals: an estimation of their global impact on mortality, length of stay and healthcare costs. Epidemiol Infect 2012; 140: 126-36.

[51] Vrijens F, Hulstaert F, Van de Sande S, Devriese S, Morales I, Parmentier Y. Hospitalacquired, laboratory-confirmed bloodstream infections: linking national surveillance data to clinical and financial hospital data to estimate increased length of stay and healthcare costs. J Hosp Infect 2010; 75: 158-62.

[52] Abdelsattar ZM, Krapohl G, Alrahmani L et al. Postoperative burden of hospital-acquired Clostridium difficile infection. Infect Control Hosp Epidemiol 2015; 36: 40-6.

[53] Bond SE, Boutlis CS, Yeo WW, Pratt WA, Orr ME, Miyakis S. The burden of healthcareassociated Clostridium difficile infection in a non-metropolitan setting. J Hosp Infect 2017; 95: 387-93.

[54] Chen Y, Glass K, Liu B, Korda RJ, Riley TV, Kirk MD. Burden of Clostridium difficile infection: Associated hospitalization in a cohort of middle-aged and older adults. Am J Infect Control 2017; 45: 508-11.

[55] Eckmann C, Wasserman M, Latif F, Roberts G, Beriot-Mathiot A. Increased Hospital Length of Stay Attributable to Clostridium difficile Infection in Patients with Four Co-morbidities: An Analysis of HospitaEur J Health Econl Episode Statistics in Four European Countries. European Journal of Health Economics 2013; 14: 835-46. 
[56] Egorova NN, Siracuse JJ, McKinsey JF, Nowygrod R. Trend, Risk Factors, and Costs of Clostridium difficile Infections in Vascular Surgery. Ann Vasc Surg 2015; 29: 792-800.

[57] Flagg A, Koch CG, Schiltz $\mathrm{N}$ et al. Analysis of Clostridium difficile infections after cardiac surgery: epidemiologic and economic implications from national data. J Thorac Cardiovasc Surg 2014; 148: 2404-9.

[58] Forster AJ, Taljaard M, Oake N, Wilson K, Roth V, van Walraven C. The effect of hospitalacquired infection with Clostridium difficile on length of stay in hospital. CMAJ 2012; 184: $37-42$.

[59] Jacob J, Wu J, Han J, Nelson DB. Clostridium difficile in an Urban, University-Affiliated LongTerm Acute-Care Hospital. Infect Control Hosp Epidemiol 2017; 38: 294-9.

[60] Keshavamurthy S, Koch CG, Fraser TG et al. Clostridium difficile infection after cardiac surgery: prevalence, morbidity, mortality, and resource utilization. J Thorac Cardiovasc Surg 2014; 148: 3157-65.e5.

[61] Lipp MJ, Nero DC, Callahan MA. Impact of hospital-acquired Clostridium difficile. J Gastroenterol Hepatol 2012; 27: 1733-7.

[62] Mitchell B, Gardner A, Barnett A, Hiller J, Graves N. The prolongation of length of stay because of Clostridium difficile infection. American Journal of Infection Control 2014; 42: 164-7.

[63] Pakyz A, Carroll NV, Harpe SE, Oinonen M, Polk RE. Economic impact of Clostridium difficile infection in a multihospital cohort of academic health centers. Pharmacotherapy 2011; 31: 546-51.

[64] Ryan P, Skally M, Duffy F et al. Evaluation of fixed and variable hospital costs due to Clostridium difficile infection: institutional incentives and directions for future research. $J$ Hosp Infect 2017; 95: 415-20.

[65] Skovrlj B, Guzman JZ, Silvestre J, Al Maaieh M, Qureshi SA. Clostridium difficile colitis in patients undergoing lumbar spine surgery. Spine (Phila Pa 1976) 2014; 39: E1167-73.

[66] Stevens VW, Khader K, Nelson RE et al. Excess Length of Stay Attributable to Clostridium difficile Infection (CDI) in the Acute Care Setting: A Multistate Model. Infect Control Hosp Epidemiol 2015; 36: 1024-30.

[67] Tabak YP, Zilberberg MD, Johannes RS, Sun X, McDonald LC. Attributable burden of hospitalonset Clostridium difficile infection: a propensity score matching study. Infect Control Hosp Epidemiol 2013; 34: 588-96.

[68] van Kleef E, Green N, Goldenberg SD et al. Excess length of stay and mortality due to Clostridium difficile infection: a multi-state modelling approach. J Hosp Infect 2014; 88: 2137.

[69] Vonberg R, Reichardt C, Behnke M, Schwab F, Zindler S, Gastmeier P. Costs of nosocomial Clostridium difficile-associated diarrhoea. J Hosp Infect 2008; 70: 15-20.

[70] Yasunaga $\mathrm{H}$, Horiguchi $\mathrm{H}$, Hashimoto $\mathrm{H}$, Matsuda S, Fushimi K. The burden of Clostridium difficile-associated disease following digestive tract surgery in Japan. J Hosp Infect 2012; 82: $175-80$.

[71] Zerey M, Paton BL, Lincourt AE, Gersin KS, Kercher KW, Heniford BT. The burden of Clostridium difficile in surgical patients in the United States. Surgical infections 2007; 8: 557.

[72] Zhang T, Lin QY, Fei JX et al. Clostridium Difficile Infection Worsen Outcome of Hospitalized Patients with Inflammatory Bowel Disease. Sci Rep 2016; 6: 29791.

[73] Anderson DJ, Kaye KS, Chen LF et al. Clinical and financial outcomes due to methicillin resistant Staphylococcus aureus surgical site infection: a multi-center matched outcomes study. PLoS ONE 2009; 4: e8305.

[74] Apisarnthanarak A, Jones M, Waterman BM, Carroll CM, Bernardi R, Fraser VJ. Risk factors for spinal surgical-site infections in a community hospital: a case-control study. Infect Control Hosp Epidemiol 2003; 24: 31-6. 
[75] Asensio A, Torres J. Quantifying excess length of postoperative stay attributable to infections: a comparison of methods. J Clin Epidemiol 1999; 52: 1249-56.

[76] Atkinson RA, Jones A, Ousey K, Stephenson J. Management and cost of surgical site infection in patients undergoing surgery for spinal metastasis. J Hosp Infect 2017; 95: 148-53.

[77] Boltz MM, Hollenbeak CS, Julian KG, Ortenzi G, Dillon PW. Hospital costs associated with surgical site infections in general and vascular surgery patients. Surgery 2011; 150: 934-42.

[78] Coskun D, Aytac J, Aydinli A, Bayer A. Mortality rate, length of stay and extra cost of sternal surgical site infections following coronary artery bypass grafting in a private medical centre in Turkey. J Hosp Infect 2005; 60: 176-9.

[79] De Angelis G, Allignol A, Murthy A et al. Multistate modelling to estimate the excess length of stay associated with meticillin-resistant Staphylococcus aureus colonisation and infection in surgical patients. J Hosp Infect 2011; 78: 86-91.

[80] Delgado-Rodriguez M, Medina-Cuadros M, Bueno-Cavanillas A, Martinez-Gallego G, Dierssen $\mathrm{T}$, Sillero-Arenas M. Comparison of two procedures to estimate the hospital stay attributable to nosocomial infection: matched cohort study versus analysis of covariance of the total unmatched cohort. J Clin Epidemiol 1997; 50: 773-8.

[81] Fukuda H, Morikane K, Kuroki M et al. Impact of surgical site infections after open and laparoscopic colon and rectal surgeries on postoperative resource consumption. Infection 2012; 40: 649-59.

[82] Gaine WJ, Ramamohan NA, Hussein NA, Hullin MG, McCreath SW. Wound infection in hip and knee arthroplasty. J Bone Joint Surg Br 2000; 82: 561-5.

[83] Geubbels EL, Mintjes-de Groot AJ, van den Berg JM, de Boer AS. An operating surveillance system of surgical-site infections in The Netherlands: results of the PREZIES national surveillance network. Preventie van Ziekenhuisinfecties door Surveillance. Infect Control Hosp Epidemiol 2000; 21: 311-8.

[84] Gonzalez-Velez AE, Romero-Martin M, Villanueva-Orbaiz R, Diaz-Agero-Perez C, RobustilloRodela A, Monge-Jodra $V$. The cost of infection in hip arthroplasty: a matched case-control study. Rev Esp Cir Ortop Traumatol 2016; 60: 227-33.

[85] Herwaldt LA, Cullen JJ, Scholz D et al. A prospective study of outcomes, healthcare resource utilization, and costs associated with postoperative nosocomial infections. InfectControl HospEpidemiol 2006; 27: 1291-8.

[86] Jenks PJ, Laurent M, McQuarry S, Watkins R. Clinical and economic burden of surgical site infection (SSI) and predicted financial consequences of elimination of SSI from an English hospital. J Hosp Infect 2014; 86: 24-33.

[87] Kusachi S, Kashimura N, Konishi T et al. Length of stay and cost for surgical site infection after abdominal and cardiac surgery in Japanese hospitals: multi-center surveillance. Surg Infect (Larchmt) 2012; 13: 257-65.

[88] Kuy S, Dua A, Desai S et al. Surgical site infections after lower extremity revascularization procedures involving groin incisions. Ann Vasc Surg 2014; 28: 53-8.

[89] Lamarsalle L, Hunt B, Schauf M, Szwarcensztein K, Valentine WJ. Evaluating the clinical and economic burden of healthcare-associated infections during hospitalization for surgery in France. Epidemiol Infect 2013; 141: 2473-82.

[90] McGarry SA, Engemann JJ, Schmader K, Sexton DJ, Kaye KS. Surgical-site infection due to Staphylococcus aureus among elderly patients: mortality, duration of hospitalization, and cost. Infect Control Hosp Epidemiol 2004; 25: 461-7.

[91] Merle V, Germain JM, Chamouni P et al. Assessment of prolonged hospital stay attributable to surgical site infections using appropriateness evaluation protocol. Am J Infect Control 2000; 28: 109-15.

[92] Monge Jodra V, Sainz de Los Terreros Soler L, Diaz-Agero Perez C, Saa Requejo CM, Plana Farras N. Excess length of stay attributable to surgical site infection following hip replacement: a nested case-control study. Infect Control Hosp Epidemiol 2006; 27: 1299-303. 
[93] Olsen MA, Butler AM, Willers DM, Gross GA, Hamilton BH, Fraser VJ. Attributable costs of surgical site infection and endometritis after low transverse cesarean delivery. InfectControl HospEpidemiol 2010; 31: 276-82.

[94] Pollard TCB, Newman JE, Barlow NJ, Price JD, Willett KM. Deep wound infection after proximal femoral fracture: consequences and costs. J Hosp Infect 2006; 63: 133-9.

[95] Campbell RS, Emons MF, Mardekian J, Girgenti D, Gaffney M, Yu H. Adverse Clinical Outcomes and Resource Utilization Associated with Methicillin-Resistant and MethicillinSensitive Staphylococcus aureus Infections after Elective Surgery. Surg Infect (Larchmt) 2015; 16: 543-52.

[96] Chacko B, Thomas K, David T, Paul H, Jeyaseelan L, Peter JV. Attributable cost of a nosocomial infection in the intensive care unit: A prospective cohort study. World journal of critical care medicine 2017; 6: 79-84.

[97] Dulworth S, Pyenson B. Healthcare-associated infections and length of hospital stay in the Medicare population. Am J Med Qual 2004; 19: 121-7.

[98] Grandini LC, Jr., Caramelli B. Infection complication portends poor prognosis in acute myocardial infarction. Arq Bras Cardiol 2006; 87: 267-74.

[99] Graves N, Weinhold D, Tong E et al. Effect of healthcare-acquired infection on length of hospital stay and cost. Infect Control Hosp Epidemiol 2007; 28: 280-92.

[100] Hassan M, Tuckman HP, Patrick RH, Kountz DS, Kohn JL. Cost of hospital-acquired infection. Hosp Top 2010; 88: 82-9.

[101] Hoogervorst-Schilp J, Langelaan M, Spreeuwenberg P, de Bruijne MC, Wagner C. Excess length of stay and economic consequences of adverse events in Dutch hospital patients. BMC Health Serv Res 2015; 15: 531.

[102] Karagozian R, Johannes RS, Sun X, Burakoff R. Increased mortality and length of stay among patients with inflammatory bowel disease and hospital-acquired infections. Clin Gastroenterol Hepatol 2010; 8: 961-5.

[103] Khan MM, Celik Y. Cost of nosocomial infection in Turkey: an estimate based on the university hospital data. Health Serv Manage Res 2001; 14: 49-54.

[104] Kollef MH, Sharpless L, Vlasnik J, Pasque C, Murphy D, Fraser VJ. The impact of nosocomial infections on patient outcomes following cardiac surgery. Chest 1997; 112: 666-75.

[105] Lee J, Imanaka Y, Sekimoto M, Ikai H, Otsubo T. Healthcare-associated infections in acute ischaemic stroke patients from 36 Japanese hospitals: risk-adjusted economic and clinical outcomes. Int J Stroke 2011; 6: 16-24.

[106] Lloyd-Smith P, Younger J, Lloyd-Smith E, Green H, Leung V, Romney MG. Economic analysis of vancomycin-resistant enterococci at a Canadian hospital: assessing attributable cost and length of stay. $J$ Hosp Infect 2013; 85: 54-9.

[107] Macedo-Viñas M, De Angelis G, Rohner P et al. Burden of meticillin-resistant Staphylococcus aureus infections at a Swiss University hospital: excess length of stay and costs. J Hosp Infect 2013; 84: 132-7.

[108] Nosrati M, Boroumand M, Tahmasebi S, Sotoudeh M, Sheikhfathollahi M, Goodarzynejad H. Excess costs associated with common healthcare-associated infections in an Iranian cardiac surgical unit. J Hosp Infect 2010; 76: 304-7.

[109] O'Keefe S, Williams K, Legare JF. Hospital-Acquired Infections After Cardiac Surgery and Current Physician Practices: A Retrospective Cohort Study. J Clin Med Res 2017; 9: 10-6.

[110] Resch A, Wilke M, Fink C. The cost of resistance: incremental cost of methicillin-resistant Staphylococcus aureus (MRSA) in German hospitals. Eur J Health Econ 2009; 10: 287-97.

[111] Trybou J, Spaepen E, Vermeulen B, Porrez L, Annemans L. Hospital-acquired infections in Belgian acute-care hospitals: financial burden of disease and potential cost savings. Acta Clin Belg 2013; 68: 199-205.

[112] Wu BU, Johannes RS, Kurtz S, Banks PA. The impact of hospital-acquired infection on outcome in acute pancreatitis. Gastroenterology 2008; 135: 816-20. 
[113] Nelson RE, Samore MH, Jones $\mathrm{M}$ et al. Reducing Time-dependent Bias in Estimates of the Attributable Cost of Health Care-associated Methicillin-resistant Staphylococcus aureus Infections: A Comparison of Three Estimation Strategies. Med Care 2015; 53: 827-34.

[114] Ingeman A, Andersen G, Hundborg HH, Svendsen ML, Johnsen SP. In-hospital medical complications, length of stay, and mortality among stroke unit patients. Stroke 2011; 42: 3214-8.

[115] Nosova K, Nuno M, Mukherjee D et al. Urinary tract infections in meningioma patients: analysis of risk factors and outcomes. J Hosp Infect 2013; 83: 132-9.

[116] Micek ST, Chew B, Hampton N, Kollef MH. A Case-Control Study Assessing the Impact of Nonventilated Hospital-Acquired Pneumonia on Patient Outcomes. Chest 2016; 150: 100814.

[117] Restrepo MI, Anzueto A, Arroliga AC et al. Economic burden of ventilator-associated pneumonia based on total resource utilization. InfectControl HospEpidemiol 2010; 31: 50915.

[118] Zhang Z, Duan J. Nosocomial pneumonia in non-invasive ventilation patients: incidence, characteristics, and outcomes. J Hosp Infect 2015; 91: 153-7.

[119] Padegimas EM, Maltenfort M, Ramsey ML, Williams GR, Parvizi J, Namdari S. Periprosthetic shoulder infection in the United States: incidence and economic burden. J Shoulder Elbow Surg 2015; 24: 741-6.

[120] Sommerfelt H, Steinsland H, van der Merwe L et al. Case/Control Studies With Follow-up: Constructing the Source Population to Estimate Effects of Risk Factors on Development, Disease, and Survival. ClinInfectDis 2012; 55: S262-S70.

[121] World Health Organization. Conceptual framework for the international classification for patient safety version 1.1: final technical report January 2009. Geneva: World Health Organization 2009.

[122] Kyne L, Hamel MB, Polavaram R, Kelly CP. Health care costs and mortality associated with nosocomial diarrhea due to Clostridium difficile. Clin Infect Dis 2002; 34: 346-53.

[123] Graves N, Barnett AG, Halton K et al. The importance of good data, analysis, and interpretation for showing the economics of reducing healthcare-associated infection. InfectControl HospEpidemiol 2011; 32: 927-37.

[124] Dick AW, Perencevich EN, Pogorzelska-Maziarz M, Zwanziger J, Larson EL, Stone PW. A decade of investment in infection prevention: A cost-effectiveness analysis. American Journal of Infection Control 2015; 43: 4-9.

[125] von Elm E, Altman DG, Egger M, Pocock SJ, Gøtzsche PC, Vandenbroucke JP. The Strengthening the Reporting of Observational Studies in Epidemiology (STROBE) statement: guidelines for reporting observational studies. Lancet 2007; 370: 1453-7.

[126] Husereau D, Drummond M, Petrou S et al. Consolidated Health Economic Evaluation Reporting Standards (CHEERS) statement. BMJ 2013; 346: f1049.

[127] Wolkewitz M, Allignol A, Harbarth S, de Angelis G, Schumacher M, Beyersmann J. Timedependent study entries and exposures in cohort studies can easily be sources of different and avoidable types of bias. J Clin Epidemiol 2012; 65: 1171-80.

[128] Beyersmann J, Wolkewitz M, Schumacher M. The impact of time-dependent bias in proportional hazards modelling. Stat Med 2008; 27: 6439-54.

[129] Barnett A, Graves N. Competing risks models and time-dependent covariates. Crit Care 2008; 12: 134.

[130] Wolkewitz M, von Cube M, Schumacher M. Multistate Modeling to Analyze Nosocomial Infection Data: An Introduction and Demonstration. Infection Control \& Hospital Epidemiology 2017; 38: 953-9.

[131] Department of Health. Reference Costs 2015-16. (accessed 2017 Jul 26). https://www.gov.uk/government/publications/nhs-reference-costs-2015-to-2016 
[132] Health Protection Scotland. Healthcare Associated Infection - Annual Report 2016. Glasgow: Health Protection Scotland 2017.

[133] Stewardson AJ, Harbarth S, Graves N, Group TS. Valuation of hospital bed-days released by infection control programs: a comparison of methods. InfectControl HospEpidemiol 2014; 35 : 1294.

[134] Allegranzi B, Bagheri Nejad S, Combescure C et al. Burden of endemic health-care-associated infection in developing countries: systematic review and meta-analysis. Lancet (London, England) 2011; 377: 228-41. 


\section{$\underline{\text { Tables }}$}

Table I: Summary of characteristics of published studies that produced estimates of excess LOS due to HAI. Where studies reported more than one HAI type we extracted all LOS estimates.

\begin{tabular}{|c|c|c|}
\hline Study Characteristics & & \\
\hline HAl type(s) Reported: & No of studies & (\%) of studies \\
\hline Bloodstream & 23 & $(19 \%)$ \\
\hline Gastro-intestinal & 22 & $(18 \%)$ \\
\hline Surgical site & 27 & $(22 \%)$ \\
\hline $\mathrm{HAI}^{*}$ & 26 & $(22 \%)$ \\
\hline Urinary tract & 10 & $(8 \%)$ \\
\hline Pneumonia & 8 & $(7 \%)$ \\
\hline Lower respiratory tract & 4 & $(3 \%)$ \\
\hline Bone and joint & 1 & $(1 \%)$ \\
\hline \multicolumn{3}{|l|}{ Primary Statistical Methodology: } \\
\hline \multicolumn{3}{|l|}{ Time-Fixed } \\
\hline Group Comparison & 14 & $(15 \%)$ \\
\hline Matching (Simple) & 31 & (34\%) \\
\hline Regression & 24 & $(26 \%)$ \\
\hline \multicolumn{3}{|l|}{ Time-varying } \\
\hline Matching (Time) & 12 & $(13 \%)$ \\
\hline Survival Analysis & 2 & $(2 \%)$ \\
\hline Multistate Model & 9 & $(10 \%)$ \\
\hline Total & 92 & $(100 \%)$ \\
\hline \multicolumn{3}{|c|}{ Included Studies by Country and Income Classification: } \\
\hline High Income & 81 & $(88 \%)$ \\
\hline Middle Income & 11 & $(12 \%)$ \\
\hline \multicolumn{3}{|l|}{ Study Design } \\
\hline Case-Control & 18 & $(20 \%)$ \\
\hline Cohort & 74 & $(80 \%)$ \\
\hline \multicolumn{3}{|l|}{ Studies' Year of Data Collection** } \\
\hline $1989-2000$ & 38 & \\
\hline $2001-2004$ & 37 & \\
\hline $2005-2008$ & 54 & \\
\hline $2009-2012$ & 43 & \\
\hline $2013-2016$ & 10 & \\
\hline
\end{tabular}

* HAI refers to studies which estimated total impact on LOS across more than one type of HAI or multiple types of HAI due to a single organism (e.g. MRSA).

**Counted if contain any data collected in these years (most studies used data collected in multiple years) 


\section{Figures}

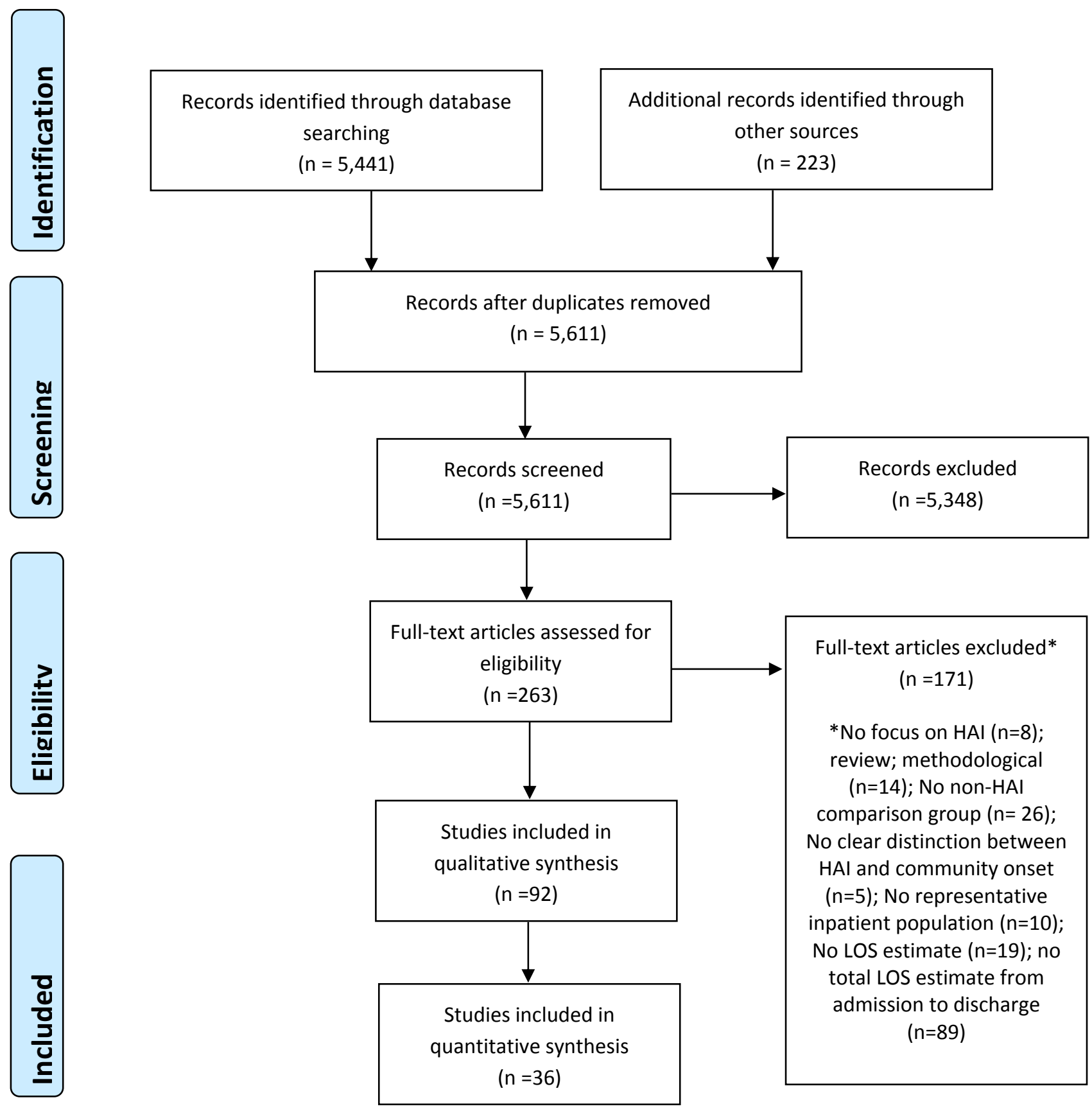

Figure 1: PRISMA Flow Diagram showing the relevant observational studies of the impact of HAI on LOS 


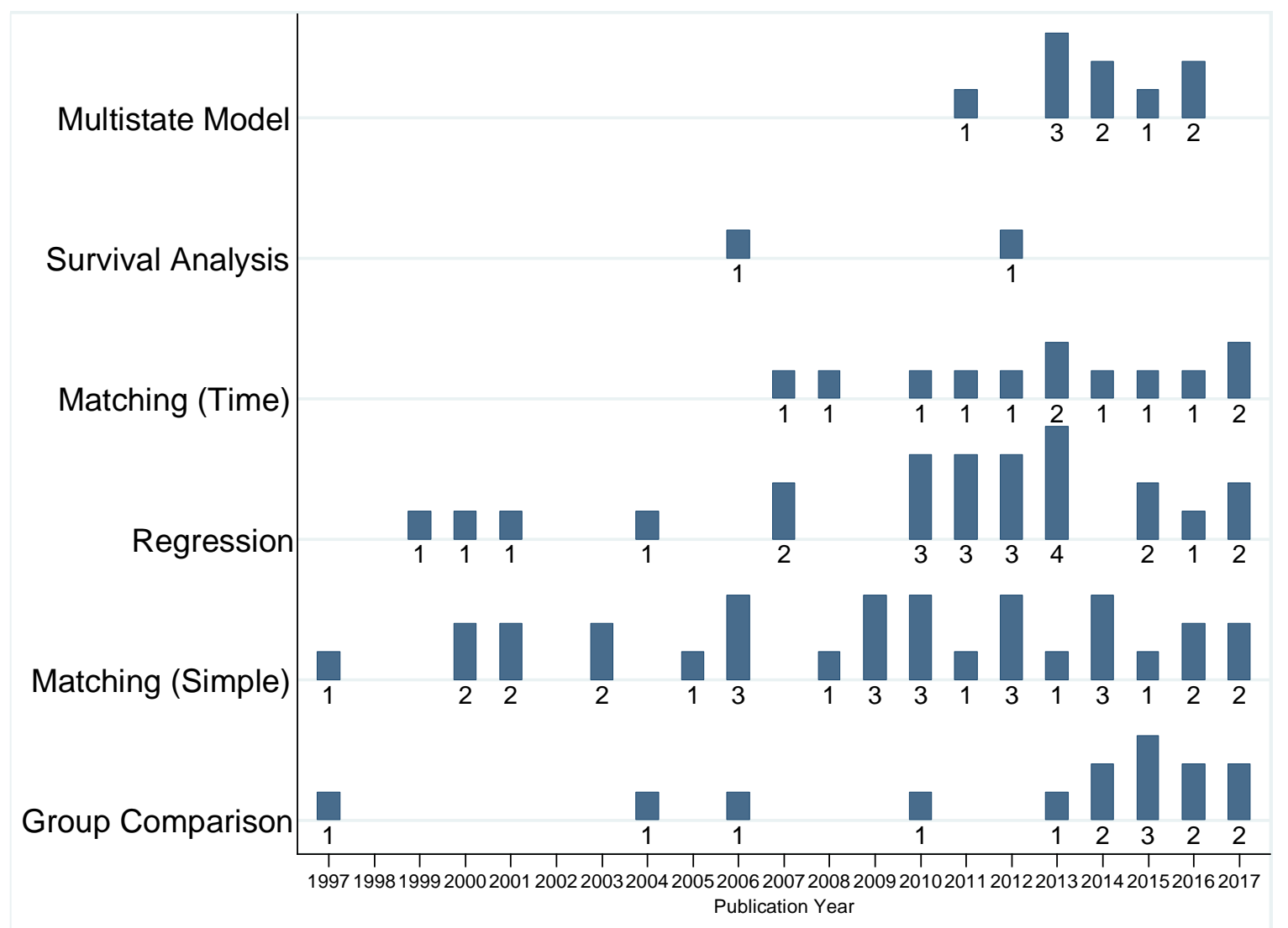

Figure 2: Articles by year of publication and statistical method. Number of studies published in the corresponding year are shown below each bar. Group comparison, Matching (Simple) and Regression are time-fixed methods. Matching (Time), Survival Analysis and Multistate Modelling are time-varying methods. 


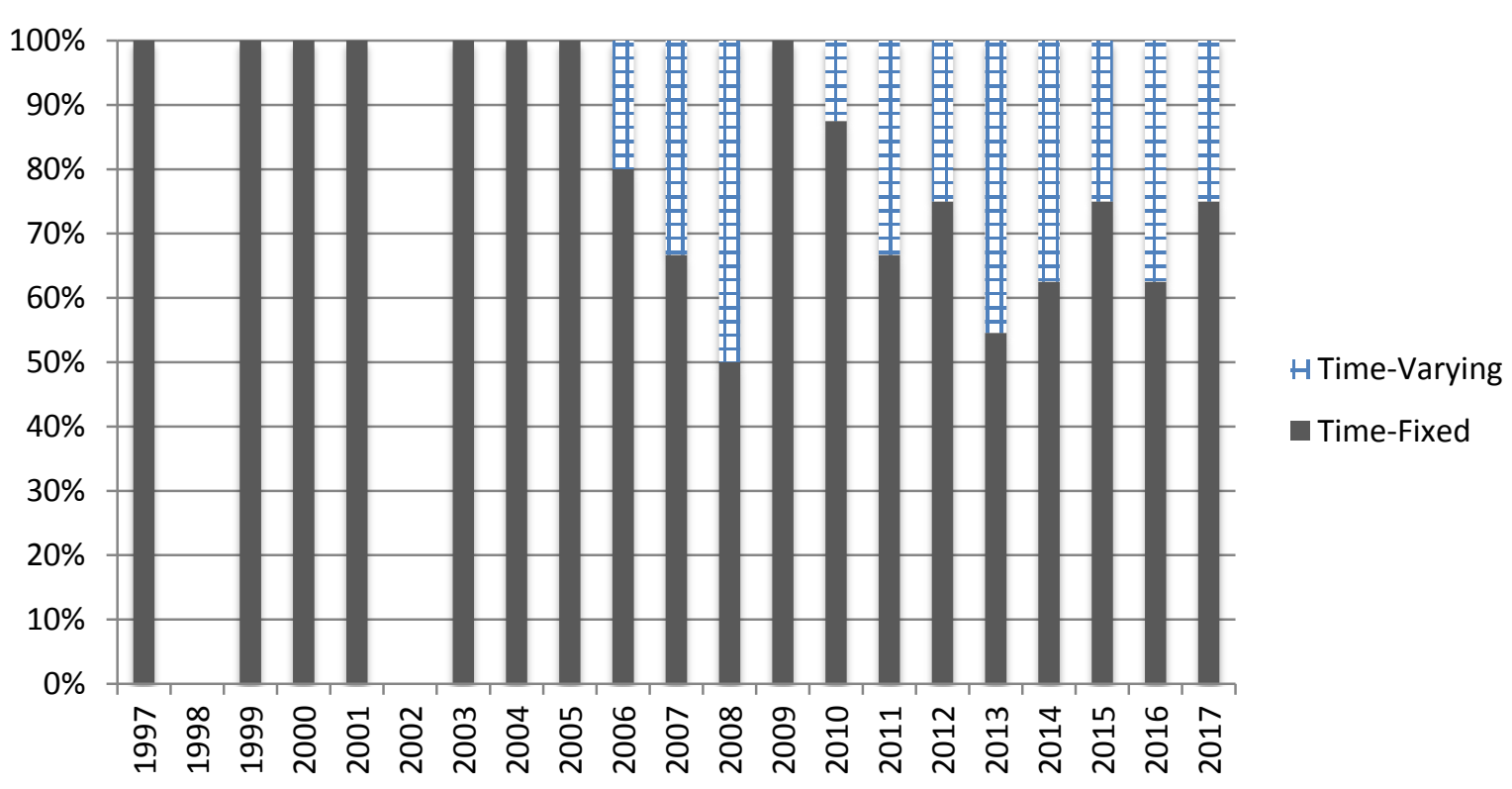

Figure 3 Articles by year of publication and time-fixed vs time-varying methodologies. 


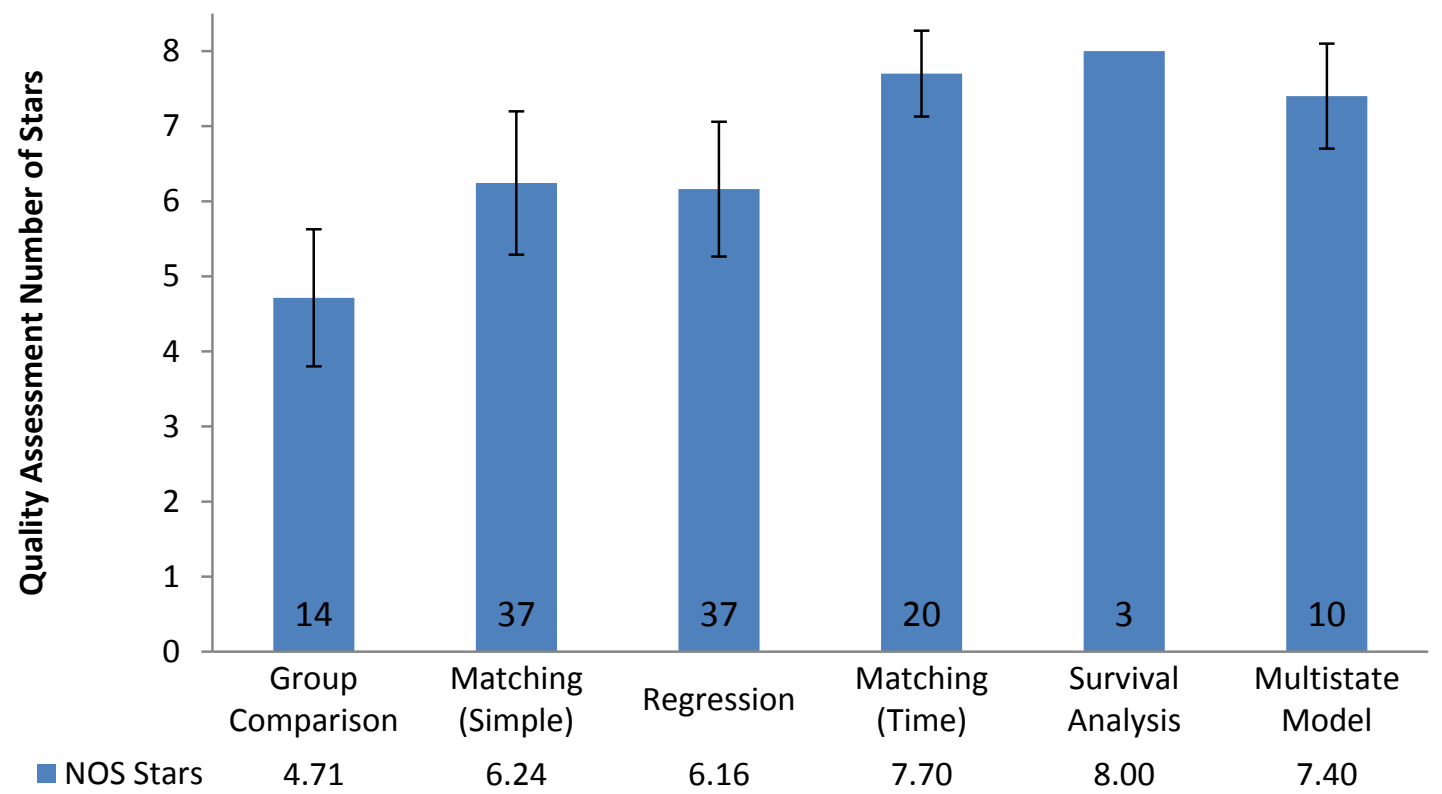

Figure 4: Quality assessment by type of statistical method. Papers quality assessed using the NOS assessment tool for case-control and cohort studies. Studies could get a maximum of 8 stars. 121 LOS estimates quality assessed in 92 studies. Number of estimates assessed in each statistical method are shown on the bottom of each bar. Mean NOS stars by method are shown below each bar. There were three LOS estimates in the Survival Analysis group which were allocated a perfect score of 8 stars. Error bars calculated from standard deviations. Group comparison, Matching (Simple) and Regression are time-fixed methods. Matching (Time), Survival Analysis and Multistate Modelling are timevarying methods. 


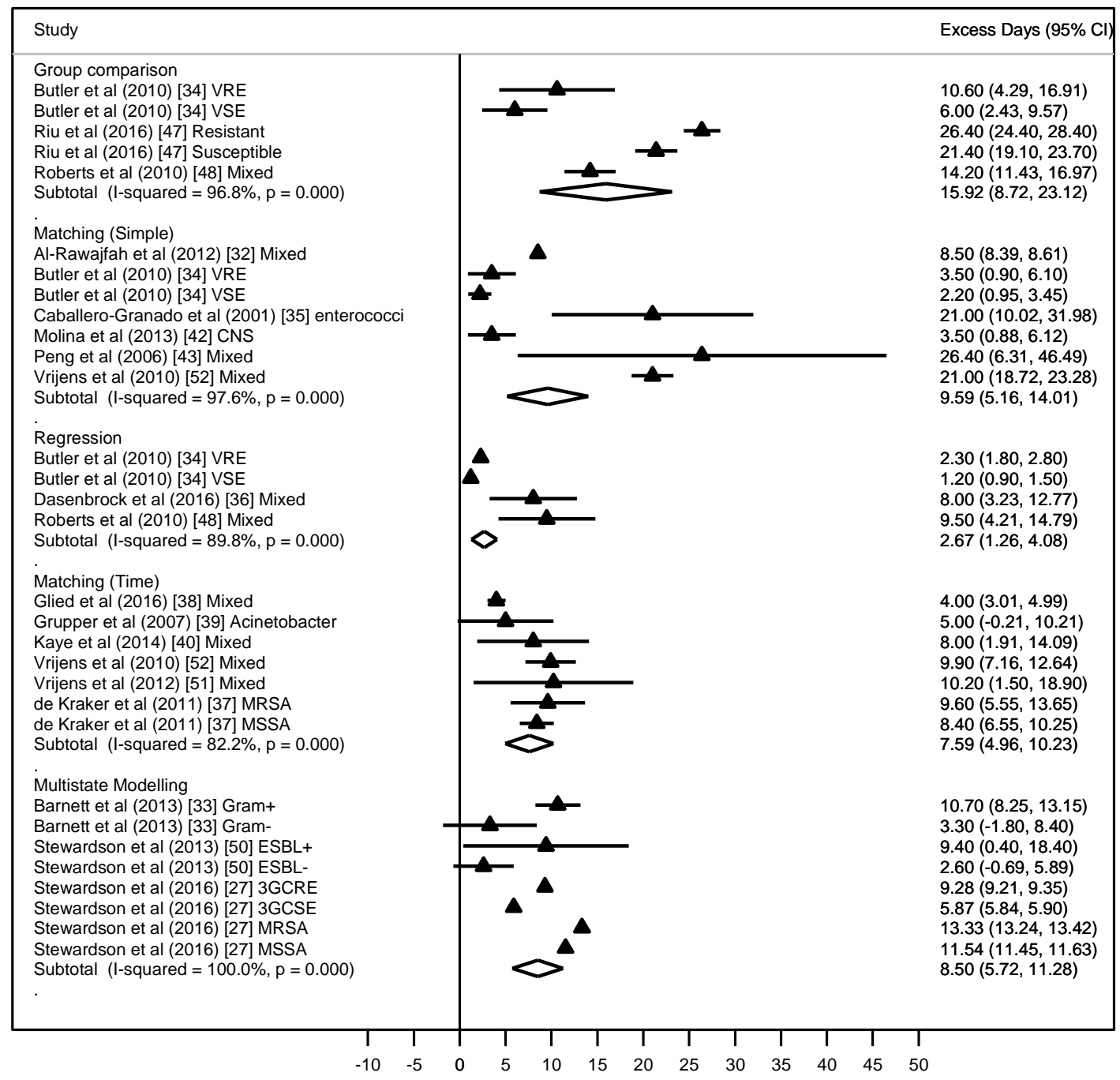

Figure 5: Excess days and 95\% Cls for the association of LOS and BSI. The triangles and horizontal lines correspond to the study-specific Excess Days estimates and $95 \%$ Cls. The diamonds represent the pooled Excess Days and $95 \% \mathrm{Cls}$ of each subgroup. The vertical solid line shows Excess Days of zero. Mixed: Range of organisms included, not separated by antimicrobial resistance. VRE: Vancomycin-resistant enterococci. VSE: Vancomycin-susceptible enterococci. CNS: Coagulase-negative staphylococci. MRSA: Methicillin-resistant Staphylococcus aureus. MSSA: Methicillin-susceptible Staphylococcus aureus. Gram+: Gram-positive bacteria. Gram-: Gram-negative bacteria. ESBL+: Extended-Spectrum $\beta$ Lactamase-Producing Enterobacteriaceae positive. ESBL-: Extended-Spectrum $\beta$-Lactamase-Producing Enterobacteriaceae negative. 3GCRE: Third-generation cephalosporin resistant Enterobacteriaceae. 3GCSE: Thirdgeneration cephalosporin susceptible Enterobacteriaceae. Enterococci: Susceptible and resistant enterococcal BSI. Acinetobacter: Susceptible and resistant Acinetobacter BSI. Group comparison, Matching (Simple) and Regression are time-fixed methods. Matching (Time), Survival Analysis and Multistate Modelling are time-varying methods. 


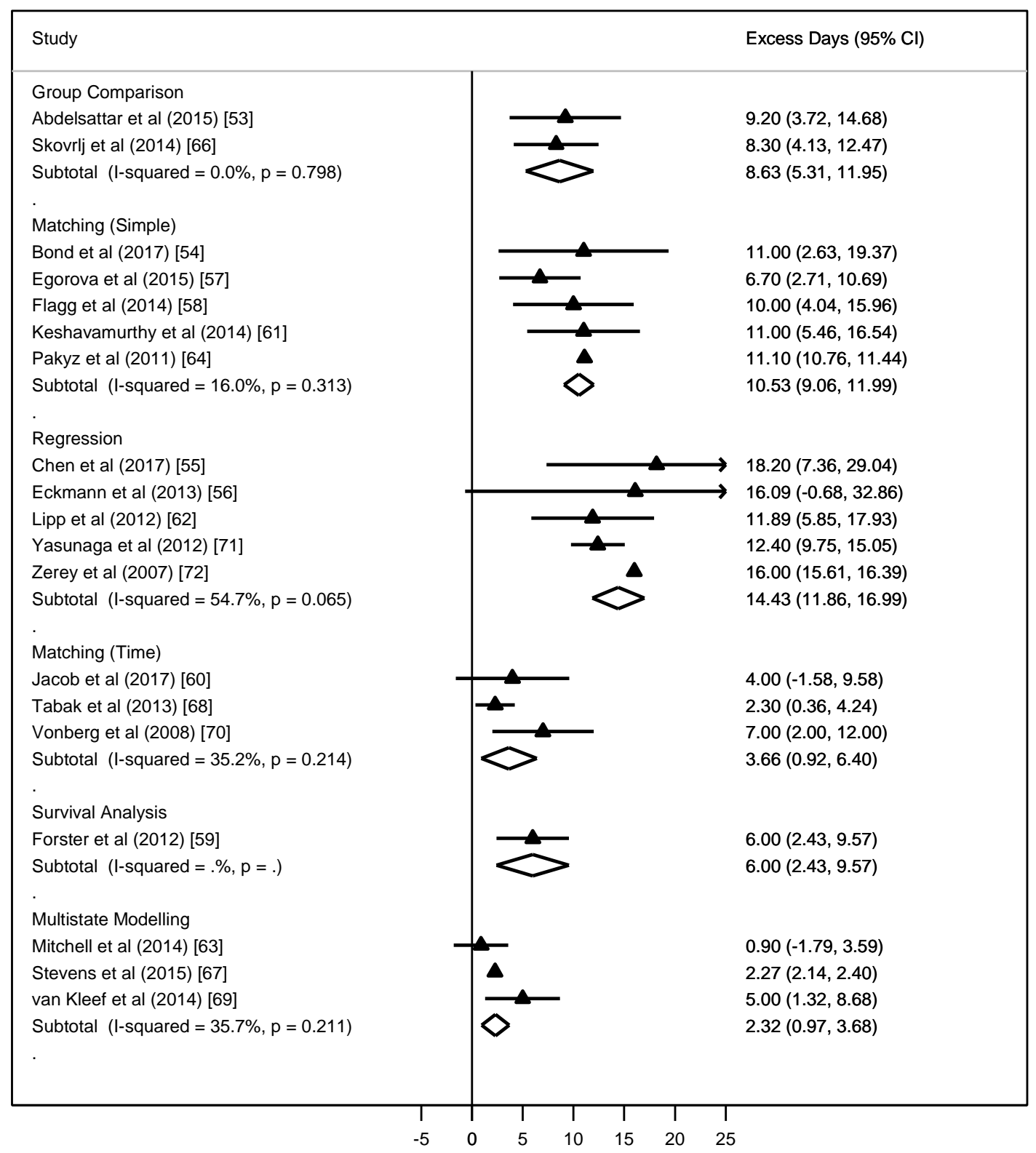

Figure 6: Excess days and $95 \% \mathrm{Cls}$ for the association of LOS and CDI. The triangles and horizontal lines correspond to the study-specific Excess Days estimates and $95 \%$ Cls. The diamonds represent the pooled Excess Days and $95 \%$ Cls of each subgroup and overall population. The vertical solid line shows Excess Days of zero. Group comparison, Matching (Simple) and Regression are time-fixed methods. Matching (Time), Survival Analysis and Multistate Modelling are timevarying methods. 


\section{Figure Legends}

Figure 7: PRISMA Flow Diagram showing the relevant observational studies of the impact of HAI on LOS

Figure 8: Articles by year of publication and statistical method. Number of studies published in the corresponding year are shown below each bar. Group comparison, Matching (Simple) and Regression are time-fixed methods. Matching (Time), Survival Analysis and Multistate Modelling are time-varying methods.

Figure 9 Articles by year of publication and time-fixed vs time-varying methodologies.

Figure 10: Quality assessment by type of statistical method. Papers quality assessed using the NOS assessment tool for case-control and cohort studies. Studies could get a maximum of 8 stars. 121 LOS estimates quality assessed in 92 studies. Number of estimates assessed in each statistical method are shown on the bottom of each bar. Mean NOS stars by method are shown below each bar. There were three LOS estimates in the Survival Analysis group which were allocated a perfect score of 8 stars. Error bars calculated from standard deviations. Group comparison, Matching (Simple) and Regression are time-fixed methods. Matching (Time), Survival Analysis and Multistate Modelling are timevarying methods.

Figure 11: Excess days and $95 \% \mathrm{Cls}$ for the association of LOS and BSI. The triangles and horizontal lines correspond to the study-specific Excess Days estimates and 95\% Cls. The diamonds represent the pooled Excess Days and $95 \% \mathrm{Cls}$ of each subgroup. The vertical solid line shows Excess Days of zero. Mixed: Range of organisms included, not separated by antimicrobial resistance. VRE: Vancomycin-resistant enterococci. VSE: Vancomycin-susceptible enterococci. CNS: Coagulase-negative staphylococci. MRSA: Methicillin-resistant Staphylococcus aureus. MSSA: Methicillin-susceptible Staphylococcus aureus. Gram+: Gram-positive bacteria. Gram-: Gram-negative bacteria. ESBL+: Extended-Spectrum $\beta$ Lactamase-Producing Enterobacteriaceae positive. ESBL-: Extended-Spectrum $\beta$-Lactamase-Producing Enterobacteriaceae negative. 3GCRE: Third-generation cephalosporin resistant Enterobacteriaceae. 3GCSE: Thirdgeneration cephalosporin susceptible Enterobacteriaceae. Enterococci: Susceptible and resistant enterococcal BSI. Acinetobacter: Susceptible and resistant Acinetobacter BSI. Group comparison, Matching (Simple) and Regression are time-fixed methods. Matching (Time), Survival Analysis and Multistate Modelling are time-varying methods.

Figure 12: Excess days and 95\% Cls for the association of LOS and CDI. The triangles and horizontal lines correspond to the study-specific Excess Days estimates and $95 \% \mathrm{Cls}$. The diamonds represent the pooled Excess Days and $95 \% \mathrm{Cls}$ of each subgroup and overall population. The vertical solid line shows Excess Days of zero. Group comparison, Matching (Simple) and Regression are time-fixed methods. Matching (Time), Survival Analysis and Multistate Modelling are timevarying methods. 


\section{Supplementary Material 1}

Studies eligible for data extraction and analysis by HAl type. Note that some studies appear in more than one HAI type.

\begin{tabular}{|c|c|c|c|c|}
\hline Authors & Study Design & $\begin{array}{l}\text { Primary Statistical } \\
\text { Methodology }\end{array}$ & Country & QA Stars \\
\hline \multicolumn{5}{|l|}{ Bloodstream Infection } \\
\hline Riu et al (2016)[46] & Retrospective cohort & Group comparison & Spain & 6 \\
\hline Al-Rawajfah et al (2012)[31] & Retrospective case-control & Matching (Simple) & USA & 4 \\
\hline $\begin{array}{l}\text { Caballero-Granado et al } \\
(2001)[34]\end{array}$ & Prospective case-control & Matching (Simple) & Spain & 6 \\
\hline Kothari et al (2009)[40] & Retrospective case-control & Matching (Simple) & India & 7 \\
\hline Molina et al (2013)[41] & Prospective case-control & Matching (Simple) & Spain & 7 \\
\hline Peng et al (2006)[42] & Retrospective cohort & Matching (Simple) & USA & 7 \\
\hline Primo et al (2012)[44] & Retrospective case-control & Matching (Simple) & Brazil & 5 \\
\hline Song et al (2003)[48] & Retrospective cohort & Matching (Simple) & USA & 6 \\
\hline Butler et al (2010)[33] & Retrospective cohort & Regression & USA & 6 \\
\hline Dasenbrock et al (2016)[35] & Retrospective cohort & Regression & USA & 5 \\
\hline Plowman et al (2001)[43] & Prospective cohort & Regression & UK & 6 \\
\hline Rattanaumpawan et al (2017)[45] & Retrospective cohort & Regression & Thailand & 7 \\
\hline Roberts et al (2010)[47] & Retrospective cohort & Regression & USA & 7 \\
\hline Al-Rawajfah et al (2013)[30] & Retrospective case-control & Matching (Time) & Jordan & 7 \\
\hline de Kraker et al (2011)[36] & Prospective cohort & Matching (Time) & Europe & 7 \\
\hline Glied et al (2016)[37] & Retrospective cohort & Matching (Time) & USA & 8 \\
\hline Grupper et al (2007)[38] & Retrospective cohort & Matching (Time) & Israel & 6 \\
\hline Kaye et al (2014)[39] & Retrospective cohort & Matching (Time) & USA & 8 \\
\hline Vrijens et al (2010)[51] & Retrospective cohort & Matching (Time) & Belgium & 8 \\
\hline Vrijens et al (2012)[50] & Retrospective cohort & Matching (Time) & Belgium & 8 \\
\hline Barnett et al (2013)[32] & Retrospective case-control & Multistate Modelling & Australia & 7 \\
\hline Stewardson et al (2013)[49] & Retrospective cohort & Multistate Modelling & Switzerland & 8 \\
\hline Stewardson et al (2016)[26] & Retrospective cohort & Multistate Modelling & Europe & 7 \\
\hline \multicolumn{5}{|l|}{ Gastrointestinal Infection } \\
\hline Abdelsattar et al (2015)[52] & Prospective cohort & Group comparison & USA & 5 \\
\hline Skovrlj et al (2014)[65] & Retrospective cohort & Group comparison & USA & 3 \\
\hline Zhang et al (2016)[72] & Prospective cohort & Group comparison & China & 5 \\
\hline Bond et al (2017)[53] & Prospective case-control & Matching (Simple) & Australia & 7 \\
\hline
\end{tabular}




\begin{tabular}{|c|c|c|c|c|}
\hline Egorova et al (2015)[56] & Retrospective cohort & Matching (Simple) & USA & 5 \\
\hline Flagg et al (2014)[57] & Retrospective cohort & Matching (Simple) & USA & 5 \\
\hline Keshavamurthy et al (2014)[60] & Prospective cohort & Matching (Simple) & USA & 7 \\
\hline Pakyz et al (2011)[63] & Retrospective case-control & Matching (Simple) & USA & 4 \\
\hline Chen et al (2017)[54] & Retrospective cohort & Regression & Australia & 6 \\
\hline Eckmann et al (2013)[55] & Retrospective cohort & Regression & UK & 7 \\
\hline Lipp et al (2012)[61] & Retrospective cohort & Regression & USA & 5 \\
\hline Yasunaga et al (2012)[70] & Retrospective cohort & Regression & Japan & 5 \\
\hline Zerey et al (2007)[71] & Retrospective cohort & Regression & USA & 5 \\
\hline Jacob et al (2017)[59] & Retrospective cohort & Matching (Time) & USA & 8 \\
\hline Ryan et al (2017)[64] & Retrospective cohort & Matching (Time) & Ireland & 7 \\
\hline Tabak et al (2013)[67] & Retrospective cohort & Matching (Time) & USA & 8 \\
\hline Vonberg et al (2008)[69] & Prospective case-control & Matching (Time) & Germany & 7 \\
\hline Vrijens et al (2012)[50] & Retrospective cohort & Matching (Time) & Belgium & 8 \\
\hline Foster et al (2012)[58] & Retrospective cohort & Survival Analysis & Canada & 8 \\
\hline Mitchell et al (2014)[62] & Retrospective cohort & Multistate Modelling & Australia & 6 \\
\hline Stevens et al (2015)[66] & Retrospective cohort & Multistate Modelling & USA & 8 \\
\hline van Kleef et al (2014)[68] & Prospective cohort & Multistate Modelling & UK & 8 \\
\hline \multicolumn{5}{|l|}{ Surgical Site Infection } \\
\hline Kuy et al (2014)[88] & Retrospective cohort & Group comparison & USA & 5 \\
\hline Lamarsalle et al (2013)[89] & Retrospective cohort & Group comparison & France & 4 \\
\hline Anderson et al (2009)[73] & Prospective case-control & Matching (Simple) & USA & 7 \\
\hline Apisarnthanarak et al (2003)[74] & Prospective case-control & Matching (Simple) & USA & 7 \\
\hline Atkinson et al (2017)[76] & Prospective cohort & Matching (Simple) & UK & 6 \\
\hline Coskun et al (2005)[78] & Prospective cohort & Matching (Simple) & Turkey & 6 \\
\hline $\begin{array}{l}\text { Delgado-Rodriguez et al } \\
(1997)[80]\end{array}$ & Prospective cohort & Matching (Simple) & Spain & 7 \\
\hline Gaine et al (2000)[82] & Prospective case-control & Matching (Simple) & UK & 6 \\
\hline Gonzalez-Velez et al (2016)[84] & Prospective case-control & Matching (Simple) & Spain & 7 \\
\hline Jenks et al (2014)[86] & Retrospective cohort & Matching (Simple) & UK & 7 \\
\hline Kusachi et al (2012)[87] & Prospective case-control & Matching (Simple) & Japan & 7 \\
\hline Merle et al (2000)[91] & Prospective cohort & Matching (Simple) & France & 7 \\
\hline Monge Jodra et al (2006)[92] & Prospective case-control & Matching (Simple) & Spain & 7 \\
\hline Olsen et al (2010)[93] & Retrospective cohort & Matching (Simple) & USA & 5 \\
\hline Peng et al (2006)[42] & Retrospective cohort & Matching (Simple) & USA & 7 \\
\hline Pollard et al (2006)[94] & Retrospective cohort & Matching (Simple) & UK & 5 \\
\hline
\end{tabular}




\begin{tabular}{|c|c|c|c|c|}
\hline Asensio and Torres (1999)[75] & Retrospective cohort & Regression & Spain & 7 \\
\hline Boltz et al (2011)[77] & Prospective cohort & Regression & USA & 7 \\
\hline Fukuda et al (2012)[81] & Retrospective cohort & Regression & Japan & 7 \\
\hline Geubbels et al (2000)[83] & Prospective cohort & Regression & Netherlands & 6 \\
\hline McGarry et al (2004)[90] & Prospective cohort & Regression & USA & 7 \\
\hline Plowman et al (2001)[43] & Prospective cohort & Regression & UK & 7 \\
\hline Roberts et al (2010)[47] & Retrospective cohort & Regression & USA & 7 \\
\hline Glied et al (2016)[37] & Retrospective cohort & Matching (Time) & USA & 8 \\
\hline Vrijens et al (2012)[50] & Retrospective cohort & Matching (Time) & Belgium & 8 \\
\hline Herwaldt et al (2006)[85] & Prospective cohort & Survival Analysis & USA & 8 \\
\hline De Angelis et al (2011)[79] & Prospective cohort & Multistate Modelling & Switzerland & 8 \\
\hline \multicolumn{5}{|l|}{ Healthcare Associated Infection } \\
\hline Dulworth and Pyenson (2004)[97] & Retrospective cohort & Group comparison & USA & 4 \\
\hline Grandini and Caramelli (2006)[98] & Retrospective cohort & Group comparison & Brazil & 6 \\
\hline Kollef et al (1997)[104] & Prospective cohort & Group comparison & USA & 5 \\
\hline Nosrati et al (2010)[108] & Prospective cohort & Group comparison & Iran & 6 \\
\hline Chacko et al (2017)[96] & Prospective cohort & Group comparison & India & 4 \\
\hline O'Keefe et al (2017)[109] & Retrospective cohort & Group comparison & Canada & 5 \\
\hline $\begin{array}{l}\text { Delgado-Rodriguez et al } \\
(1997)[80]\end{array}$ & Prospective cohort & Matching (Simple) & Spain & 7 \\
\hline Khan and Celik (2001)[103] & Prospective cohort & Matching (Simple) & Turkey & 6 \\
\hline Resch et al (2009)[110] & Retrospective cohort & Matching (Simple) & Germany & 5 \\
\hline Karagozian et al (2010)[102] & Retrospective cohort & Matching (Simple) & USA & 7 \\
\hline Wu et al (2008)[112] & Retrospective cohort & Matching (Simple) & USA & 5 \\
\hline Campbell et al (2015)[95] & Retrospective cohort & Regression & USA & 6 \\
\hline Graves et al (2007)[99] & Prospective cohort & Regression & Australia & 7 \\
\hline Hassan et al (2010)[100] & Retrospective cohort & Regression & USA & 5 \\
\hline $\begin{array}{l}\text { Hoogervorst-Schilp et al } \\
(2015)[101]\end{array}$ & Retrospective cohort & Regression & Netherlands & 6 \\
\hline Lee et al (2011)[105] & Retrospective cohort & Regression & Japan & 5 \\
\hline Lloyd-Smith et al (2013)[106] & Retrospective case-control & Regression & Canada & 5 \\
\hline Plowman et al (2001)[43] & Prospective cohort & Regression & UK & 6 \\
\hline Roberts et al (2010)[47] & Retrospective cohort & Regression & USA & 7 \\
\hline Trybou et al (2013)[111] & Retrospective cohort & Regression & Belgium & 7 \\
\hline Nelson et al (2015)[113] & Retrospective cohort & Matching (Time) & USA & 8 \\
\hline Vrijens et al (2012)[50] & Retrospective cohort & Matching (Time) & Belgium & 8 \\
\hline Herwaldt et al (2006)[85] & Prospective cohort & Survival Analysis & USA & 8 \\
\hline
\end{tabular}




\begin{tabular}{|c|c|c|c|c|}
\hline Arefian et al (2016)[4] & Prospective cohort & Multistate Modelling & Germany & 7 \\
\hline De Angelis et al (2011)[79] & Prospective cohort & Multistate Modelling & Switzerland & 8 \\
\hline Macedo-Viñas et al (2013)[107] & Retrospective cohort & Multistate Modelling & Switzerland & 7 \\
\hline \multicolumn{5}{|l|}{ Urinary Tract Infection } \\
\hline $\begin{array}{l}\text { Delgado-Rodriguez et al } \\
\text { (1997)[80] }\end{array}$ & Prospective cohort & Matching (Simple) & Spain & 7 \\
\hline Peng et al (2006)[42] & Retrospective cohort & Matching (Simple) & USA & 7 \\
\hline Dasenbrock et al (2016)[35] & Retrospective cohort & Regression & USA & 5 \\
\hline Ingeman et al (2011)[114] & Retrospective cohort & Regression & Denmark & 5 \\
\hline Nosova et al (2013)[115] & Retrospective cohort & Regression & USA & 5 \\
\hline Plowman et al (2001)[43] & Prospective cohort & Regression & UK & 7 \\
\hline Rattanaumpawan et al (2017)[45] & Retrospective cohort & Regression & Thailand & 7 \\
\hline Roberts et al (2010)[47] & Retrospective cohort & Regression & USA & 7 \\
\hline Glied et al (2016)[37] & Retrospective cohort & Matching (Time) & USA & 8 \\
\hline Vrijens et al (2012)[50] & Retrospective cohort & Matching (Time) & Belgium & 8 \\
\hline \multicolumn{5}{|l|}{ Pneumonia } \\
\hline Zhang and Duan (2015)[118] & Prospective cohort & Group comparison & China & 4 \\
\hline Micek et al (2016)[116] & Retrospective case-control & Matching (Simple) & USA & 6 \\
\hline Peng et al (2006)[42] & Retrospective cohort & Matching (Simple) & USA & 7 \\
\hline Restrepo et al (2010)[117] & Retrospective cohort & Matching (Simple) & USA & 6 \\
\hline Dasenbrock et al (2016)[35] & Retrospective cohort & Regression & USA & 5 \\
\hline Ingeman et al (2011)[114] & Retrospective cohort & Regression & Denmark & 5 \\
\hline Roberts et al (2010)[47] & Retrospective cohort & Regression & USA & 7 \\
\hline Glied et al (2016)[37] & Retrospective cohort & Matching (Time) & USA & 8 \\
\hline \multicolumn{5}{|c|}{ Lower Respiratory Tract Infection (other than pneumonia) } \\
\hline $\begin{array}{l}\text { Delgado-Rodriguez et al } \\
\text { (1997)[80] }\end{array}$ & Prospective cohort & Matching (Simple) & Spain & 7 \\
\hline Graves et al (2007)[99] & Prospective cohort & Regression & Australia & 7 \\
\hline Plowman et al (2001)[43] & Prospective cohort & Regression & UK & 7 \\
\hline Vrijens et al (2012)[50] & Retrospective cohort & Matching (Time) & Belgium & 8 \\
\hline \multicolumn{5}{|l|}{ Bone and Joint Infection } \\
\hline Padegimas et al (2015)[119] & Retrospective cohort & Group comparison & USA & 4 \\
\hline
\end{tabular}




\section{Supplementary Material 2}

The PubMed search strategy is presented in three parts. The first part has cross-infection keywords and Mesh terms. The second part has HAl related keywords and Mesh terms. The third part has economic and length of stay keywords and Mesh terms.

\section{Cross Infection}

((“Cross Infection”[Mesh] OR (cross infection*[tiab]) OR (healthcare associated infection*[tiab]) OR (health care associated infection*[tiab]) OR (hospital acquired infection*[tiab]) OR (hospital-acquired infection*[tiab]) OR (hospital associated infection*[tiab]) OR (healthcare-associated infection*[tiab]) OR (healthcare acquired infection*[tiab]) OR (health care acquired infection*[tiab]) OR (nosocomia*[tiab]) OR "Disease Transmission, Infectious"[Mesh] OR (cross transmission[tiab]) OR (infectious disease transmission[tiab]))

\section{Healthcare Associated Infections}

("Catheter-Related Infections"[Mesh] OR (catheter related infection*[tiab]) OR (catheter acquired infection*[tiab]) OR (catheter associated infection*[tiab]) OR (CAUTI[tiab]) OR (device related infection*[tiab]) OR (device acquired infection*[tiab]) OR (device associated infection*[tiab]) OR (central line related bloodstream infection*[tiab]) OR (central line acquired bloodstream infection*[tiab]) OR (central line associated bloodstream infection*[tiab]) OR (CLABSI[tiab]) OR(CRBSI[tiab]) OR "bacteremia"[Mesh] OR (bacteremia[tiab]) OR “Methicillin-Resistant Staphylococcus aureus"[Mesh] OR "Clostridium difficile"[Mesh] OR "Clostridium Infections"[Mesh] OR "Enterocolitis, Pseudomembranous"[Mesh] OR (Clostridium difficile[tiab]) OR (c. diff*[tiab]) OR (CDI[tiab]) OR (CDAD[tiab]) OR (gastrointestinal infection*[tiab]) OR "norovirus"[Mesh] OR "Pneumonia, Ventilator-Associated"[Mesh] OR “Respiratory Tract Infections" [Mesh] OR (ventilator acquired pneumonia[tiab]) OR (nosocomial pneumonia[tiab]) OR (ventilator associated pneumonia[tiab]) OR "sepsis"[Mesh] OR "Urinary Tract Infections"[Mesh] OR "Urinary Catheterization"[Mesh] OR (urinary catheter*[tiab]) OR "Surgical Wound Infection"[Mesh] OR (surgical site infection*[tiab]) OR (postoperative infection*[tiab]) OR (postsurgical infection*[tiab]) OR (wound infection*[tiab]) OR (sternal wound infection*[tiab]) OR (postoperative[tiab]) OR (post-surgical[tiab]) OR “Cardiovascular Infections"[Mesh] OR "endocarditis, bacterial”[Mesh] OR (cardiovascular infection*[tiab]) OR (endocarditis[tiab]) OR (pericarditis[tiab]) OR "Staphylococcal Skin Infections"[Mesh] OR (skin infection*[tiab]) OR (soft tissue infection*[tiab]) OR “Osteomyelitis"[Mesh] OR (bone infection*[tiab]) OR (joint infection*[tiab]) OR "central nervous system infections"[Mesh] OR "eye infections"[Mesh] OR (eye infection*[tiab]) OR "otitis"[Mesh] OR ear infection*[tiab] OR "Sinusitis"[Mesh] OR (mouth infection*[tiab]) OR "reproductive tract infections"[Mesh] OR (reproductive tract infection*[tiab])))

\section{Economics and length of stay}

("Costs and Cost Analysis"[Mesh] OR "Health Care Costs"[Mesh] OR "Health Expenditures"[Mesh] OR "Direct Service Costs"[Mesh] OR "Hospital Costs"[Mesh] OR "Employer Health Costs"[Mesh] OR "Drug Costs"[Mesh] OR "Cost of Illness"[Mesh] OR "Economics"[Mesh] OR "Length of Stay"[Mesh] OR (length of stay[tiab]) OR (length of hospitalization[tiab]) OR (hospitalization length[tiab]) OR (duration of stay[tiab])) 


\section{Supplementary Material 3}

\section{Newcastle-Ottawa quality assessment tool}

This scale has been adapted from the Newcastle-Ottawa Quality Assessment Scale to perform quality assessment (QA) in the systematic review. In this version of NOS we define the exposure as $\mathrm{HAl}$ and the outcome as discharge or total duration of hospital stay.

\section{COHORT STUDIES}

Selection: (Maximum 5 stars)

1) Representativeness of the sample:

a) Truly representative of the average in the target population (e.g. inpatient hospital specialty)**

b) Somewhat representative of the average in the target population*

c) Selected group of users.

d) No description of the sampling strategy.

2) Sample size:

a) Adequate sample size to be able to draw conclusions about impact*

b) Very small sample size.

3) Ascertainment of the exposure:

a) Case definitions applied to records (eg electronic medical records, microbiology results)**

b) Nurses, doctors or laboratory tests only to identifying exposure*

c) Exposure assumed retrospectively purely due to treatment (i.e. antibiotics) or with ICD codes

d) written, self-reported or self-assessed

e) no description

\section{continues next page}


Comparability: (Maximum 1 stars)

1) The subjects in different outcome groups are comparable, based on the study design or analysis. Confounding factors are controlled.

a) The study controls for additional factors (such as age, comorbidities, device use/not an exhaustive list of factors)*

b) The study does not control for additional factors.

Outcome: (Maximum 2 stars)

1) Assessment of the outcome:

a) Clearly reported total duration of hospitalisation*

b) Duration of hospitalisation is reported but unclear if it refers to total.

2) $\mathrm{HAl}$ treated as a time-dependent exposure:

a) The statistical methods used to analyse the data control for bias that can occur if baseline immeasurable time-dependent factors that cannot be recorded at baseline and change value after patient observation starts are analysed as if they were known and available at baseline.*

b) The statistical methods do not treat $\mathrm{HAl}$ as a time-dependent exposure.

For case-control studies use items on next page 


\section{CASE-CONTROL STUDIES}

Adapted from the Newcastle-Ottawa Quality Assessment Scale. Cases refer to HAI patients and control patients refer to non-HAl patients.

Selection: (Maximum 5 stars)

1) Is the case definition adequate?

a) Case definitions applied to records (eg electronic medical records, microbiology results)**

b) Nurses, doctors or laboratory tests only to identifying exposure*

c) Exposure assumed retrospectively purely due to treatment (i.e. antibiotics) or with ICD codes

d) written, self-reported or self-assessed

e) no description

2) Representativeness of the cases

a) consecutive or obviously representative series of cases*

b) potential for selection biases or not stated

3) Selection of Controls

a) controls from same target population chosen prospectively**

b) controls from diverse population chosen retrospectively*

c) no description

Comparability (Maximum 1 stars)

1) Comparability of cases and controls on the basis of the design or analysis

a) The study controls for additional factors. ${ }^{*}$

b) The study does not control for additional factors.

Outcome (Maximum 2 stars)

1) Assessment of the outcome:

a) Clearly reported total duration of hospitalisation*

b) Duration of hospitalisation is reported but unclear if it refers to total.

2) HAl treated as a time-dependent exposure:

a) The statistical methods used to analyse the data control for bias that can occur if baseline immeasurable time-dependent factors that cannot be recorded at baseline and change value after patient observation starts are analysed as if they were known and available at baseline.*

b) The statistical methods do not treat HAl as a time-dependent exposure. 


\section{Supplementary Material 4}

Table shows quality assessment breakdown for each study. Quality assessment was performed with the Newcastle-Ottawa Scale (NOS). Headings on table are named after items in the cohort/case control versions of NOS where applicable. Each study could be awarded a maximum of 8 stars.

\begin{tabular}{|c|c|c|c|c|c|c|c|}
\hline Authors & $\begin{array}{l}\text { Sample } \\
\text { representative/Case } \\
\text { definitions adequate }\end{array}$ & $\begin{array}{l}\text { Sample } \\
\text { size/Representativeness } \\
\text { of cases }\end{array}$ & $\begin{array}{l}\text { Ascertainment of } \\
\text { exposure/Selection } \\
\text { controls }\end{array}$ & $\begin{array}{l}\text { Study controls for } \\
\text { additional factors }\end{array}$ & $\begin{array}{l}\text { Assessment of } \\
\text { outcome }\end{array}$ & $\begin{array}{l}\text { HAl treated as a time } \\
\text { varying exposure }\end{array}$ & Total \\
\hline \multicolumn{8}{|l|}{ Bloodstream Infection } \\
\hline Riu et al (2016)[46] & 2 & 1 & 2 & 0 & 1 & 0 & 6 \\
\hline Al-Rawajfah et al (2012)[31] & 0 & 1 & 1 & 1 & 1 & 0 & 4 \\
\hline Caballero-Granado et al (2001)[34] & 2 & 1 & 2 & 0 & 1 & 0 & 6 \\
\hline Kothari et al (2009)[40] & 2 & 1 & 2 & 1 & 1 & 0 & 7 \\
\hline Molina et al (2013)[41] & 2 & 1 & 2 & 1 & 1 & 0 & 7 \\
\hline Peng et al (2006)[42] & 2 & 1 & 2 & 1 & 1 & 0 & 7 \\
\hline Primo et al (2012)[44] & 2 & 1 & 1 & 0 & 1 & 0 & 5 \\
\hline Song et al (2003)[48] & 2 & 1 & 2 & 0 & 1 & 0 & 6 \\
\hline Butler et al (2010)[33] & 2 & 1 & 1 & 1 & 1 & 0 & 6 \\
\hline Dasenbrock et al (2016)[35] & 2 & 1 & 0 & 1 & 1 & 0 & 5 \\
\hline Plowman et al (2001)[43] & 2 & 0 & 2 & 1 & 1 & 0 & 6 \\
\hline Rattanaumpawan et al (2017)[45] & 2 & 1 & 2 & 1 & 1 & 0 & 7 \\
\hline Roberts et al (2010)[47] & 2 & 1 & 2 & 1 & 1 & 0 & 7 \\
\hline Al-Rawajfah et al (2013)[30] & 2 & 1 & 1 & 1 & 1 & 1 & 7 \\
\hline
\end{tabular}




\begin{tabular}{|c|c|c|c|c|c|c|c|}
\hline de Kraker et al (2011)[36] & 2 & 1 & 1 & 1 & 1 & 1 & 7 \\
\hline Glied et al (2016)[37] & 2 & 1 & 2 & 1 & 1 & 1 & 8 \\
\hline Grupper et al (2007)[38] & 2 & 0 & 1 & 1 & 1 & 1 & 6 \\
\hline Kaye et al (2014)[39] & 2 & 1 & 2 & 1 & 1 & 1 & 8 \\
\hline Vrijens et al (2010)[51] & 2 & 1 & 2 & 1 & 1 & 1 & 8 \\
\hline Vrijens et al (2012)[50] & 2 & 1 & 2 & 1 & 1 & 1 & 8 \\
\hline Barnett et al (2013)[32] & 2 & 1 & 1 & 1 & 1 & 1 & 7 \\
\hline Stewardson et al (2013)[49] & 2 & 1 & 2 & 1 & 1 & 1 & 8 \\
\hline Stewardson et al (2016)[26] & 2 & 1 & 1 & 1 & 1 & 1 & 7 \\
\hline \multicolumn{8}{|l|}{ Gastrointestinal Infection } \\
\hline Abdelsattar et al (2015)[52] & 2 & 1 & 1 & 0 & 1 & 0 & 5 \\
\hline Skovrlj et al (2014)[65] & 2 & 1 & 0 & 0 & 0 & 0 & 3 \\
\hline Zhang et al (2016)[72] & 2 & 1 & 1 & 0 & 1 & 0 & 5 \\
\hline Bond et al (2017)[53] & 2 & 1 & 2 & 1 & 1 & 0 & 7 \\
\hline Egorova et al (2015)[56] & 2 & 1 & 0 & 1 & 1 & 0 & 5 \\
\hline Flagg et al (2014)[57] & 2 & 1 & 0 & 1 & 1 & 0 & 5 \\
\hline Keshavamurthy et al (2014)[60] & 2 & 1 & 2 & 1 & 1 & 0 & 7 \\
\hline Pakyz et al (2011)[63] & 0 & 1 & 1 & 1 & 1 & 0 & 4 \\
\hline Chen et al (2017)[54] & 2 & 1 & 1 & 1 & 1 & 0 & 6 \\
\hline Eckmann et al (2013)[55] & 2 & 1 & 2 & 1 & 1 & 0 & 7 \\
\hline Lipp et al (2012)[61] & 2 & 1 & 0 & 1 & 1 & 0 & 5 \\
\hline Yasunaga et al (2012)[70] & 2 & 1 & 0 & 1 & 1 & 0 & 5 \\
\hline
\end{tabular}




\begin{tabular}{|c|c|c|c|c|c|c|c|}
\hline Zerey et al (2007)[71] & 2 & 1 & 0 & 1 & 1 & 0 & 5 \\
\hline Jacob et al (2017)[59] & 2 & 1 & 2 & 1 & 1 & 1 & 8 \\
\hline Ryan et al (2017)[64] & 2 & 1 & 1 & 1 & 1 & 1 & 7 \\
\hline Tabak et al (2013)[67] & 2 & 1 & 2 & 1 & 1 & 1 & 8 \\
\hline Vonberg et al (2008)[69] & 1 & 1 & 2 & 1 & 1 & 1 & 7 \\
\hline Vrijens et al (2012)[50] & 2 & 1 & 2 & 1 & 1 & 1 & 8 \\
\hline Foster et al (2012)[58] & 2 & 1 & 2 & 1 & 1 & 1 & 8 \\
\hline Mitchell et al (2014)[62] & 2 & 1 & 1 & 0 & 1 & 1 & 6 \\
\hline Stevens et al (2015)[66] & 2 & 1 & 2 & 1 & 1 & 1 & 8 \\
\hline van Kleef et al (2014)[68] & 2 & 1 & 2 & 1 & 1 & 1 & 8 \\
\hline \multicolumn{8}{|l|}{ Surgical Site Infection } \\
\hline Kuy et al (2014)[88] & 2 & 0 & 2 & 0 & 1 & 0 & 5 \\
\hline Lamarsalle et al (2013)[89] & 2 & 1 & 0 & 0 & 1 & 0 & 4 \\
\hline Anderson et al (2009)[73] & 2 & 1 & 2 & 1 & 1 & 0 & 7 \\
\hline Apisarnthanarak et al (2003)[74] & 2 & 1 & 2 & 1 & 1 & 0 & 7 \\
\hline Atkinson et al (2017)[76] & 2 & 0 & 2 & 1 & 1 & 0 & 6 \\
\hline Coskun et al (2005)[78] & 2 & 0 & 2 & 1 & 1 & 0 & 6 \\
\hline Delgado-Rodriguez et al (1997)[80] & 2 & 1 & 2 & 1 & 1 & 0 & 7 \\
\hline Gaine et al (2000)[82] & 1 & 1 & 2 & 1 & 1 & 0 & 6 \\
\hline Gonzalez-Velez et al (2016)[84] & 2 & 1 & 2 & 1 & 1 & 0 & 7 \\
\hline Jenks et al (2014)[86] & 2 & 1 & 2 & 1 & 1 & 0 & 7 \\
\hline Kusachi et al (2012)[87] & 2 & 1 & 2 & 1 & 1 & 0 & 7 \\
\hline
\end{tabular}




\begin{tabular}{|c|c|c|c|c|c|c|c|}
\hline Merle et al (2000)[91] & 2 & 1 & 2 & 1 & 1 & 0 & 7 \\
\hline Monge Jodra et al (2006)[92] & 2 & 1 & 2 & 1 & 1 & 0 & 7 \\
\hline Olsen et al (2010)[93] & 2 & 1 & 0 & 1 & 1 & 0 & 5 \\
\hline Peng et al (2006)[42] & 2 & 1 & 2 & 1 & 1 & 0 & 7 \\
\hline Pollard et al (2006)[94] & 2 & 0 & 1 & 1 & 1 & 0 & 5 \\
\hline Asensio and Torres (1999)[75] & 2 & 1 & 2 & 1 & 1 & 0 & 7 \\
\hline Boltz et al (2011)[77] & 2 & 1 & 2 & 1 & 1 & 0 & 7 \\
\hline Fukuda et al (2012)[81] & 2 & 1 & 2 & 1 & 1 & 0 & 7 \\
\hline Geubbels et al (2000)[83] & 2 & 1 & 1 & 1 & 1 & 0 & 6 \\
\hline McGarry et al (2004)[90] & 2 & 1 & 2 & 1 & 1 & 0 & 7 \\
\hline Plowman et al (2001)[43] & 2 & 1 & 2 & 1 & 1 & 0 & 7 \\
\hline Roberts et al (2010)[47] & 2 & 1 & 2 & 1 & 1 & 0 & 7 \\
\hline Glied et al (2016)[37] & 2 & 1 & 2 & 1 & 1 & 1 & 8 \\
\hline Vrijens et al (2012)[50] & 2 & 1 & 2 & 1 & 1 & 1 & 8 \\
\hline Herwaldt et al (2006)[85] & 2 & 1 & 2 & 1 & 1 & 1 & 8 \\
\hline De Angelis et al (2011)[79] & 2 & 1 & 2 & 1 & 1 & 1 & 8 \\
\hline \multicolumn{8}{|l|}{ Healthcare Associated Infection } \\
\hline Dulworth and Pyenson (2004)[97] & 2 & 1 & 0 & 0 & 1 & 0 & 4 \\
\hline Grandini and Caramelli (2006)[98] & 2 & 1 & 2 & 0 & 1 & 0 & 6 \\
\hline Kollef et al (1997)[104] & 2 & 0 & 2 & 0 & 1 & 0 & 5 \\
\hline Nosrati et al (2010)[108] & 2 & 1 & 2 & 0 & 1 & 0 & 6 \\
\hline Chacko et al (2017)[96] & 2 & 0 & 1 & 0 & 1 & 0 & 4 \\
\hline
\end{tabular}




\begin{tabular}{|c|c|c|c|c|c|c|c|}
\hline O'Keefe et al (2017)[109] & 2 & 1 & 1 & 0 & 1 & 0 & 5 \\
\hline Delgado-Rodriguez et al (1997)[80] & 2 & 1 & 2 & 1 & 1 & 0 & 7 \\
\hline Khan and Celik (2001)[103] & 2 & 1 & 1 & 1 & 1 & 0 & 6 \\
\hline Resch et al (2009)[110] & 2 & 1 & 0 & 1 & 1 & 0 & 5 \\
\hline Karagozian et al (2010)[102] & 2 & 1 & 2 & 1 & 1 & 0 & 7 \\
\hline Wu et al (2008)[112] & 2 & 1 & 0 & 1 & 1 & 0 & 5 \\
\hline Campbell et al (2015)[95] & 2 & 1 & 1 & 1 & 1 & 0 & 6 \\
\hline Graves et al (2007)[99] & 2 & 1 & 2 & 1 & 1 & 0 & 7 \\
\hline Hassan et al (2010)[100] & 2 & 1 & 0 & 1 & 1 & 0 & 5 \\
\hline $\begin{array}{l}\text { Hoogervorst-Schilp et al } \\
(2015)[101]\end{array}$ & 2 & 1 & 1 & 1 & 1 & 0 & 6 \\
\hline Lee et al (2011)[105] & 2 & 1 & 0 & 1 & 1 & 0 & 5 \\
\hline Lloyd-Smith et al (2013)[106] & 1 & 1 & 1 & 1 & 1 & 0 & 5 \\
\hline Plowman et al (2001)[43] & 2 & 1 & 1 & 1 & 1 & 0 & 6 \\
\hline Roberts et al (2010)[47] & 2 & 1 & 2 & 1 & 1 & 0 & 7 \\
\hline Trybou et al (2013)[111] & 2 & 1 & 2 & 1 & 1 & 0 & 7 \\
\hline Nelson et al (2015)[113] & 2 & 1 & 2 & 1 & 1 & 1 & 8 \\
\hline Vrijens et al (2012)[50] & 2 & 1 & 2 & 1 & 1 & 1 & 8 \\
\hline Herwaldt et al (2006)[85] & 2 & 1 & 2 & 1 & 1 & 1 & 8 \\
\hline Arefian et al (2016)[4] & 2 & 1 & 2 & 0 & 1 & 1 & 7 \\
\hline De Angelis et al (2011)[79] & 2 & 1 & 2 & 1 & 1 & 1 & 8 \\
\hline Macedo-Viñas et al (2013)[107] & 2 & 1 & 1 & 1 & 1 & 1 & 7 \\
\hline \multicolumn{8}{|l|}{ Urinary Tract Infection } \\
\hline
\end{tabular}




\begin{tabular}{|c|c|c|c|c|c|c|c|}
\hline Delgado-Rodriguez et al (1997)[80] & 2 & 1 & 2 & 1 & 1 & 0 & 7 \\
\hline Peng et al (2006)[42] & 2 & 1 & 2 & 1 & 1 & 0 & 7 \\
\hline Dasenbrock et al (2016)[35] & 2 & 1 & 0 & 1 & 1 & 0 & 5 \\
\hline Ingeman et al (2011)[114] & 2 & 1 & 0 & 1 & 1 & 0 & 5 \\
\hline Nosova et al (2013)[115] & 2 & 1 & 0 & 1 & 1 & 0 & 5 \\
\hline Plowman et al (2001)[43] & 2 & 1 & 2 & 1 & 1 & 0 & 7 \\
\hline Rattanaumpawan et al (2017)[45] & 2 & 1 & 2 & 1 & 1 & 0 & 7 \\
\hline Roberts et al (2010)[47] & 2 & 1 & 2 & 1 & 1 & 0 & 7 \\
\hline Glied et al (2016)[37] & 2 & 1 & 2 & 1 & 1 & 1 & 8 \\
\hline Vrijens et al (2012)[50] & 2 & 1 & 2 & 1 & 1 & 1 & 8 \\
\hline \multicolumn{8}{|l|}{ Pneumonia } \\
\hline Zhang and Duan (2015)[118] & 2 & 0 & 1 & 0 & 1 & 0 & 4 \\
\hline Micek et al (2016)[116] & 2 & 1 & 1 & 1 & 1 & 0 & 6 \\
\hline Peng et al (2006)[42] & 2 & 1 & 2 & 1 & 1 & 0 & 7 \\
\hline Restrepo et al (2010)[117] & 2 & 1 & 1 & 1 & 1 & 0 & 6 \\
\hline Dasenbrock et al (2016)[35] & 2 & 1 & 0 & 1 & 1 & 0 & 5 \\
\hline Ingeman et al (2011)[114] & 2 & 1 & 0 & 1 & 1 & 0 & 5 \\
\hline Roberts et al (2010)[47] & 2 & 1 & 2 & 1 & 1 & 0 & 7 \\
\hline Glied et al (2016)[37] & 2 & 1 & 2 & 1 & 1 & 1 & 8 \\
\hline \multicolumn{8}{|c|}{ Lower Respiratory Tract Other Infection } \\
\hline Delgado-Rodriguez et al (1997)[80] & 2 & 1 & 2 & 1 & 1 & 0 & 7 \\
\hline Graves et al (2007)[99] & 2 & 1 & 2 & 1 & 1 & 0 & 7 \\
\hline
\end{tabular}




\begin{tabular}{|l|l|c|c|c|c|c|c|}
\hline Plowman et al (2001)[43] & 2 & 1 & 2 & 1 & 1 & 0 \\
\hline Vrijens et al (2012)[50] & 2 & 1 & 2 & 1 & 1 \\
\hline Bone and Joint Infection & 2 & 1 & 0 & 0 & 1 & 0 \\
\hline Padegimas et al (2015)[119] & & & \\
\hline
\end{tabular}




\section{Supplementary Material 5}

Details of Statistical Methods in the Systematic Review

\begin{tabular}{|c|c|c|c|c|}
\hline Statistical Method & Description & Advantages & Disadvantages & Studies \\
\hline Group Comparison & $\begin{array}{l}\text { Naive comparison of means } \\
\text { between an infected and an } \\
\text { uninfected group. Simple method } \\
\text { of analysis that takes advantage } \\
\text { of raw data. The groups may not } \\
\text { be similar due to differing } \\
\text { characteristics (e.g. age, } \\
\text { comorbidities) of patients in the } \\
\text { HAl group. }\end{array}$ & $\begin{array}{l}\text { Easy to use and only requires very } \\
\text { basic data such as the presence of } \\
\text { HAl or not which is possible from } \\
\text { routine data and may not require } \\
\text { data collection. }\end{array}$ & $\begin{array}{l}\text { Leads to biased estimates } \\
\text { because patients in the infected } \\
\text { group tend to be sicker and } \\
\text { ignores time-exposure. Suffers } \\
\text { from selection and time- } \\
\text { dependent bias. }\end{array}$ & $\begin{array}{l}{[46,52,65} \\
72,88,89 \\
96-98,104 \\
108,109 \\
118,119]\end{array}$ \\
\hline Matching (Simple) & $\begin{array}{l}\text { Matching methods are very } \\
\text { popular and include one to one or } \\
\text { to more than one matching and } \\
\text { matching using propensity scores. } \\
\text { Usually matching methods } \\
\text { compare mean LOS between the } \\
\text { two matched groups and "simple" } \\
\text { here denotes matching on any } \\
\text { characteristic other than the time } \\
\text { a patient has stayed in hospital up } \\
\text { to the point of infection (time to } \\
\text { infection). }\end{array}$ & $\begin{array}{l}\text { Easy to use and there are many } \\
\text { techniques available to match } \\
\text { cases to controls. Usual matching } \\
\text { factors include: Age, sex, } \\
\text { comorbidities and ward or } \\
\text { admission type. It is possible to } \\
\text { use other statistical techniques on } \\
\text { a matched sample. }\end{array}$ & $\begin{array}{l}\text { Simple matching when estimating } \\
\text { the extra LOS due to infection } \\
\text { gives biased estimates due to } \\
\text { time-dependent bias. This bias } \\
\text { occurs because the time before } \\
\text { infection is used when estimating } \\
\text { the extra LOS. There is also a } \\
\text { trade-off between accuracy and } \\
\text { maximising successful matches. }\end{array}$ & $\begin{array}{l}{[31,34,40-} \\
42,44,48 \\
53,56,57 \\
60,63,73 \\
74,76,78 \\
80,82,84 \\
86,87,91- \\
94,102,103 \\
110,112 \\
116,117]\end{array}$ \\
\hline Regression & $\begin{array}{l}\text { These methods estimate LOS } \\
\text { attributable to HAI by controlling } \\
\text { for a range of patient } \\
\text { characteristics and comorbidities } \\
\text { using linear regression }\end{array}$ & $\begin{array}{l}\text { Fairly straightforward methods } \\
\text { that can be used to estimate the } \\
\text { impact of HAI on LOS. Ease of } \\
\text { estimation and interpretation. } \\
\text { Ease of controlling for } \\
\text { comorbidities. }\end{array}$ & $\begin{array}{l}\text { Regression methods do not } \\
\text { control for the timing of events so } \\
\text { they suffer from time-dependent } \\
\text { bias. }\end{array}$ & $\begin{array}{l}{[33,35,43} \\
45,47,54 \\
55,61,70 \\
71,75,77, \\
81,83,90 \\
95,99-101 \\
105,106 \\
111,114 \\
115]\end{array}$ \\
\hline Matching (Time) & $\begin{array}{l}\text { Methods that primarily match on } \\
\text { the time to infection for } \\
\text { controlling time-dependent HAI } \\
\text { exposure. Controls are required to } \\
\text { have spent as much time in } \\
\text { hospital as the case at the time of } \\
\text { infection. Other matching factors } \\
\text { include age, sex, comorbidities. }\end{array}$ & $\begin{array}{l}\text { In addition to usual factors } \\
\text { matching can include exposure } \\
\text { time. Matching using incidence } \\
\text { density sampling, which also } \\
\text { matches on time to infection, has } \\
\text { been suggested as the best way to } \\
\text { mitigate time-dependent bias. }\end{array}$ & $\begin{array}{l}\text { Simply adding time to infection as } \\
\text { a matching factor will not } \\
\text { completely eliminate time- } \\
\text { dependent bias. Incidence density } \\
\text { matching performs better but it is } \\
\text { a complicated procedure which is } \\
\text { second best to truly time-varying } \\
\text { methods such as multistate } \\
\text { modelling. }\end{array}$ & $\begin{array}{l}{[30,36-39,} \\
50,51,59, \\
64,67,69, \\
113]\end{array}$ \\
\hline Survival Analysis & $\begin{array}{l}\text { Cox survival models treating } \mathrm{HAI} \\
\text { as time-fixed covariate but can be } \\
\text { adapted to control for time- } \\
\text { dependent bias. }\end{array}$ & $\begin{array}{l}\text { Survival methods can be adapted } \\
\text { for time-dependent analysis using } \\
\text { Cox models producing unbiased } \\
\text { estimates. Can adjust for } \\
\text { comorbidities. }\end{array}$ & $\begin{array}{l}\text { Survival methods require more in } \\
\text { depth statistical knowledge and } \\
\text { data manipulation to control for } \\
\text { time dependence. Proportional } \\
\text { hazards models use strong } \\
\text { assumptions that are not always } \\
\text { realistic. }\end{array}$ & {$[58,85]$} \\
\hline Multistate Modelling & $\begin{array}{l}\text { Patient data are modelled } \\
\text { between a set of states over time } \\
\text { such as HAl and discharge. A } \\
\text { survival analysis is then run for } \\
\text { every transition (a change from } \\
\text { one state to the other such as } \\
\text { hospital to HAl or discharged). }\end{array}$ & $\begin{array}{l}\text { This method treats } \mathrm{HAl} \text { as a time- } \\
\text { dependent exposure therefore } \\
\text { properly controlling for the } \\
\text { occurrence of events over the } \\
\text { course of time. Competing-risks } \\
\text { can be analysed at the same time. } \\
\text { Basic multistate analysis can be } \\
\text { performed with a pocket } \\
\text { calculator. }\end{array}$ & $\begin{array}{l}\text { Multistate modelling can be } \\
\text { complicated and requires data } \\
\text { preparation and specialised } \\
\text { software to be able to control for } \\
\text { other important covariates such } \\
\text { as comorbidities. Even then } \\
\text { controlling for characteristics can } \\
\text { only be done indirectly. }\end{array}$ & $\begin{array}{l}{[4,26,32,49,} \\
62,66,68, \\
79,107]\end{array}$ \\
\hline
\end{tabular}




\section{Author contributions}

SM: Led on manuscript development, design of literature search, data extraction, data analysis, statistical analysis and quality assessment.

SS: Contributed on manuscript development, design of literature search, data extraction, data analysis, and quality assessment.

SD: Read, edited and commented on initial analysis; shaped, commented and revised subsequent drafts.

NG: Read, edited and commented on initial analysis; shaped, commented and revised subsequent drafts.

HM: Contributed on manuscript development and shaped commented and revised subsequent drafts.

AM: Contributed on data extraction, quality assessment and commented and revised subsequent drafts.

CR: Contributed on statistical analysis and revised commented and revised subsequent drafts.

JR: Contributed on design of literature search and commented and revised subsequent drafts. 